\begin{tabular}{|c|l|}
\hline Title & $\begin{array}{l}\text { Distinctive and critical roles for cellular immunity and immune inflammatory response in the immunopathology of } \\
\text { Sendai virus infection in mice }\end{array}$ \\
\hline Author(s) & Simon, Ayo Y ila; Sasaki, Nobuya; Ichii, Osamu; Kajino, Kiichi; Kon, Y asuhiro; A gui, Takashi \\
\hline Citation & $\begin{array}{l}\text { Microbes and Infection, 13(8-9), 783.797 } \\
\text { https://doi.org/10.1016/.micinf.2011.04.003 }\end{array}$ \\
\hline Issue Date & 2011-08 \\
\hline Doc URL & http://hdl.handle.net/2115/46940 \\
\hline Type & article (author version) \\
\hline File Information & MI138-8_783.797.pdf \\
\hline
\end{tabular}

Instructions for use 


\section{Distinctive and critical roles for cellular immunity and immune- inflammatory response in the immunopathology of Sendai virus infection in mice}

\section{Ayo Yila Simon ${ }^{\mathrm{a} *}$, Nobuya Sasaki ${ }^{\mathrm{a}}$, Osamu Ichiib, Kiichi Kajino ${ }^{\mathrm{c}}$, Yasuhiro Kon $^{\mathbf{b}}$,Takashi Agui ${ }^{\mathrm{a}}$}

${ }^{a}$ Laboratory of Laboratory Animal Science and Medicine, Department of Disease Control, Graduate School of Veterinary Medicine, Hokkaido University, Kita 18, Nishi 9, Kita-ku, Sapporo, Hokkaido 060-0818, Japan.

${ }^{\mathbf{b}}$ Laboratory of Anatomy, Department of Biomedical Sciences, Graduate School of Veterinary Medicine, Hokkaido University Kita-18, Nishi-9, Kita-ku, Sapporo 060-0818, Japan.

${ }^{\mathrm{c}}$ Department of Collaboration and Education, Hokkaido University Research Center for Zoonosis Control, Kita-20, Nishi-10, Kita-ku, Sapporo, 001-0020, Japan

*Corresponding Author Mailing Address: Laboratory of Laboratory Animal Science and Medicine, Department of Disease Control, Graduate School of Veterinary Medicine, Hokkaido University, Kita-18, Nishi-9, Kita-ku, Sapporo 060-0818, Japan

E-mail: syila523@hotmail.com

Tel: +81-11-706-5106; Fax +81-11-706-5106

Word count: Abstract 191, Text 5,124 


\section{Abstract}

Respiratory viral infections results in severe pulmonary injury, to which host immune response may be a significant contributor. At present, it is not entirely clear the extent to which lung injury is a necessary consequence of host defense. In this report, we use functional genomics approach to characterize the key roles of cellular immunity and immune-inflammatory response in the immunopathology of Sendai virus infection in resistant $\mathrm{C} 57 \mathrm{BL} / 6 \mathrm{~J}$ and susceptible $\mathrm{DBA} / 2 \mathrm{~J}$ mice. Infected mice manifested an immune-inflammatory response characterized by the pulmonary influx of neutrophils and mononuclear cells. DBA/2J mice mounted a vigorous immune response, with significant up-regulation of cytokine/chemokine genes in two successive waves through the course of infection. Whereas, C57BL/6J mice displayed an efficient immune response with less severe pathology and clusters of immune-inflammatory responsive genes were exclusively up-regulated on day 4 in this strain. Overall, DBA/2J mice exhibited a dysregulated hyper-inflammatory cytokine/chemokine cascades that does not limit viral spread resulting in a predisposition to severe lung pathology. This response is similar to severe human respiratory paramyxovirus infections, which will serve as a model for the elucidation of hyper-immune inflammatory response that result to severe immunopathology in respiratory viral infections.

Keywords: Cellular immunity; Immune-inflammatory response; Gene expression analysis; immunopathology; Sendai virus (HVJ); Inbred mouse 


\section{Introduction}

Respiratory viral infections are a leading cause of severe respiratory illness in humans, especially among children [1]. The severity varies from non-clinical or mild upper respiratory tract infections to acute lower respiratory tract infections that may lead to hospitalization and sometimes death [2], suggesting that individual susceptibility contributes to disease severity. In addition, accompanying the clinical manifestations of the disease, children with acute respiratory viral infection have elevated levels of serum cytokines that correlate with viral replication in the respiratory tract. The occurrence of this "cytokine storm" is thought to contribute to the severity of the disease caused by these viruses [3 - 6].

Sendai virus $(\mathrm{SeV})$ is the murine counterpart of human parainfluenza virus 1 (HPIV1) and these two viruses share high-sequence homology and antigenic cross-reactivity [7, 8]. $\mathrm{SeV}$ was reported to infect nonhuman primates, and theoretically can cause zoonotic disease in humans [9]. In addition, $\mathrm{SeV}$ infection in mice has been used to study the pathogenesis of human respiratory viral infections. Furthermore, the recombinant $\mathrm{SeV}$ is under consideration as a vaccine candidate for human respiratory paramyxovirus infections [10], however, understanding the host immune response to $\mathrm{SeV}$ will lead to careful design of vaccines against respiratory viral infections. $\mathrm{SeV}$ and other respiratory paramyxoviruses cause respiratory diseases in their hosts that range from mild to severe forms; with the greatest morbidity and mortality occurring in immunocompromised hosts $[11,12]$. The variation in susceptibility to these viruses is not only due to the restriction of viral infection and replication, also results from a number of aberrations or differences in the humoral, cell-mediated and host transcriptional immune responses. 
Respiratory viral infections, especially among children, are characterized by bronchiolitis and airway occlusion, which are postulated to be characteristically immunopathological because significant numbers of inflammatory cells are recruited and activated in the lungs $[13,14]$. Recent studies have demonstrated that inflammatory mediators play essential roles in enhancing respiratory viral pathologies [15-19]; however, several of these mediators have not yet been identified. The contribution of host immune responses to the pathologies observed during respiratory viral infections opens up the potential for therapeutic alternatives based on the suppression of pathogenic immune response. T cells have been demonstrated to be an indispensable part of this pulmonary inflammatory infiltrate [13, 14]. Therefore, inflammatory mediators that recruit these cells into the lung during respiratory viral infections are strong candidates as therapeutic targets [14].

In this report, we examine $\mathrm{C} 57 \mathrm{BL} / 6 \mathrm{~J}$ and $\mathrm{DBA} / 2 \mathrm{~J}$ mice, representing the two extreme responses to $\mathrm{SeV}$ infection, to understand the contribution of the host immune response to the development lung pathology after respiratory viral infection. Transcriptional profiling of the infected lungs of these mice paired with the lungs of an uninfected mouse and harvested during different stages of the disease, allowed for the correlation of the host immune response with the viral load and resulting in severe lung pathology. Our results define the trends in the immune response and classified immune mediators that are poorly associated with severe immuno-pathology because of host response to respiratory viral infections. Here, we provide support for efforts to harness cytokine/chemokine and receptor genes immune regulation, $\mathrm{T}$ cell cytolytic function in immune therapy and vaccine design for the control of human respiratory viral infections. 


\section{Materials and methods}

\subsection{Mice and viral infections}

Specific pathogen-free (-8-week-old-) female C57BL/6J and DBA/2J mice were purchased from Japan SLC (Hamamatsu, Japan). The MN strain of SeV was a kind gift from Prof. Hiroshi Iwai of Rakuno Gakuen University, Ebetsu, Japan. Virus stock seeding and mice infection were performed as previously described [20]. Mice from each strain were divided into four groups for sampling on days 2, 4, 8 and 14 after infection; aged matched DBA/2J mice were use as controls. At all indicated time points, mice were sacrificed by intra-peritoneal injection of pentobarbital sodium (Somnopentyl, Schering-Plough Animal Health, NJ) followed by cervical dislocation. The Institutional Animal Care and Use committee of Hokkaido University approved all mice experimental protocols.

\subsection{Bronchoalveolar lavage and differential cell counts}

Mice from each group were sacrificed at the indicated time points $(n=4$ per group). Bronchoalveolar lavage fluid (BALF) samples were collected and processed for total and differential cell counts as previously described [19]. For cytokine analysis, samples were centrifuged at $800-\times \mathrm{g}$ for $10 \mathrm{~min}$ and the supernatants were stored at $-80^{\circ} \mathrm{C}$. Cell counts were performed in triplicate and the results were expressed as mean $\pm \mathrm{SE}$ values for each group

\subsection{Determination of viral titer in the lungs of Sendai virus-infected mice}

The viral replication level in the lung tissue of all groups was determined by plaque assay on LLC-MK2 cells and real-time quantitative RT-PCR, as described previously $[9,21,24]$. Briefly, mice ( $n=4$ per group) were sacrificed, and the right lung was weighed, homogenized in $10 \%$ PBS and clarified at 3,000 $\mathrm{g}$ for $10 \mathrm{~min}$. The 
supernatant was used for virus titration in plaque assays on LLC-MK2 cells. To detect viral RNA, total RNAs were obtained from the homogenized lung tissue of all groups at the indicated time points ( $n=4$ per group) using TRIzol reagent (Invitrogen, Carlsbad, CA). RNA samples for each group were refined using an RNeasy Micro Kit (Qiagen, GmbH Germany), and further treated with Turbo DNase (Ambion, Foster, CA) for DNA digestion and elimination. Next, cDNA was synthesized from RNAs templates using ReverTra Ace (Toyobo, Osaka, Japan) and an oligo dT primer. Quantitative real-time PCR analysis was performed using the Brilliant SYBR Green QPCR master mix and a real-time thermal cycler (Mx 3000; Stratagene, Santa Clara, CA). Relative quantification of mRNA was normalized to the expression of the Actb gene. The viral load present in each sample was calculated using a standard curve, and differences in lung viral titers between groups following natural log-transformation of the data were analyzed. The primers used were TCTGTTGAAGGCTGTCATGC and GAATGGGTtATCCGGGAGTT for SeV (accession no.M30202) and TGTTACCAACTGGGACGACA and GGGGTGTTGAAGGTCTCAAA for the Actb gene (accession no. NM_007393).

\subsection{Histopathological analysis of Sendai virus-infected mice}

Histopathological methods were employed as described previously [21]. Lungs were embedded in paraffin and sections were cut 5- $\mu \mathrm{m}$ thick in duplicate, stained with hematoxylin-eosin and examined by light microscopy by two independent Veterinary pathologists (Laboratory of Veterinary Pathology) who were blinded to the experimental study groups. The degree of distribution and severity of inflammatory infiltrates/structural alterations were examined around small airways and adjacent blood vessels and changes were graded on a scale of 1-6 (Normal: 1; slight/ mild: 2; moderately severe: 4; and severe/high: 6). Pathology scores for the lung sections were 
averaged and analyzed as the pathological index. Values were expressed as mean \pm SE values for each group.

2.5 Cytokine analysis of the lung lavage fluid of Sendai virus-infected mice

BALF protein expression levels of mouse inflammatory cytokines IL-1 $\alpha$, IL-1 $\beta$, IL-2, IL-4, IL-6, IL-10, IL-12, IL-17 $\alpha$, IFN- $\gamma$, TNF- $\alpha$, G-CSF and GM-CSF were analyzed using a Multi-Analyte ELISA array Kit profiler (SABiosciences, Frederick, $\mathrm{MD)}$ according to the manufacturer's protocol. Values were expressed as mean $\pm \mathrm{SE}$ for each group in two separate measurements.

2.6 FACS analysis of surface and intracellular cytokine staining of $T$ lymphocytes subsets of lung lavage fluid

Cells collected by lung lavage from infected-mice ( $n=4$ per group) were pooled, centrifuged, and resuspended in DMEM (Invitrogen, Carlsbad, CA), and an aliquots of $1 \times 10^{6}$ cells $/ 100 \mu 1$ was used for each analysis. Cells were stimulated with the stimulation solution that contains DMEM (Invitrogen, Carlsbad, CA), PMA (Sigma-Aldrich, Switzerland), A23187 (Sigma-Aldrich, Switzerland), Brefeldin A (BioLegend, San Diego, CA). And incubated at $37^{\circ} \mathrm{C}$ for $4 \mathrm{hrs}$, washed with FACS buffer consisting of $1 \times$ PBS, $0.1 \%$ sodium azide and 1\% FBS (BioLegend, San Diego, CA) and blocked with monoclonal antibody to the FcRIII/II receptor. Cell surface staining was conducted according to standard protocols with fluorescent antibodies directed against the following molecules CD4 (PE-conjugated anti-rat), CD8 (FITC-conjugated anti-rat), CD49b (biotin anti-mouse Ly108, streptavidin-APC) and IFN- $\gamma$ (APC-anti-mouse IFN- $\gamma$ antibody) all purchased from BioLegend (San Diego, CA). For intracellular IFN- $\gamma$ staining, cells were fixed in $4 \%$ paraformaldehyde and permeablized with $0.5 \%$ saponin, thereafter stained with anti-IFN- $\gamma$ monoclonal antibody. All flow cytometric studies were performed on a FACSCalibur flow 
cytometry unit (BD Biosciences, Ontario, Canada), and 10,000-100,000 events of interest were recorded for each sample. Samples were analyzed with FACS FlowJo software (TreeStar, San Carlos, CA), and gates based on isotype control staining were used to identify the percentage of cells bearing the markers of a specific linage.

\subsection{Gene expression analysis of lungs of Sendai virus-infected mice}

Total RNA isolation and preparation was performed as described above. For gene expression, analysis $1 \mu \mathrm{g}$ of each total RNA sample was synthesize and converted into first-strand cDNAs using $\mathrm{RT}^{2}$ PCR Array First Strand Kit (SABiosciences, Frederick, MD). Each $\mathrm{RT}^{2}$ Profiler PCR Array was performed in duplicate in a 96-well format using $10 \mu \mathrm{l}$ of cDNA targeting the mRNA levels of 84 Mouse Inflammatory Cytokines/Chemokines and Receptors, (SuperArray Bioscience Corporation; catalog no \#PAMM-011-12A), according to the manufacturer's protocol. The complete list of genes analyzed is available online at www.sabiosciences.com/ArrayList. The quantitative $\mathrm{RT}^{2}$-PCR array was run on an MX 300 thermal cycler (Stratagene, La Jolla, CA). Data analysis was performed using the manufacturer's integrated web-based software package for the $\mathrm{RT}^{2} \mathrm{PCR}$ Array System using $\Delta \Delta \mathrm{Ct}$ based fold-change calculations. The expression level of the mRNA of each gene was normalized against the expression of Gusb, Hprt1, Hsp90ab1, Gapdh, and Actb, which were considered housekeeping genes. Changes in gene expression were analyzed by $t$-test using appropriate cutoff criteria. A 10-fold induction or repression of expression, with a $P$ value of $<0.05$, was considered to represent significantly up- or down-regulated gene expression. We further characterized gene expression patterns in $\mathrm{C} 57 \mathrm{BL} / 6 \mathrm{~J}, \mathrm{DBA} / 2 \mathrm{~J}$ and control mice by carrying out gene cluster analysis of the indicated time points, generating a $2 \mathrm{D}$ gene tree

using an average linkage clustering heat map method (SuperArray RT $^{2}$ PCR Array Data 
Analysis Web-base Software). The dendrogram illustrates the hierarchical time points of the lungs of each mouse group, and the average cut off for fold changes in gene expression was considered significant at $\mathrm{P}<0.001$.

\subsection{Statistical analysis}

Statistical comparisons were performed using Graph Pad Prism v5.02 software and Students t-test or one-way ANOVA was employed to determine the difference between experimental groups. Differences were considered significant at $P \leq 0.05$ and all values where applicable, were expressed mean $\pm \mathrm{SE}$.

\section{Results}

\subsection{Disease progression and development of lung pathology}

Previously, we and others $[20,21]$ have demonstrated that intranasal infection with $1 \times 10^{3} \mathrm{TCID}_{50} \mathrm{SeV}$ (lethal dose) resulted in a transient weight loss reaching a nadir 7 - 8 days after infection in both $\mathrm{C} 57 \mathrm{BL} / 6 \mathrm{~J}$ and $\mathrm{DBA} / 2 \mathrm{~J}$ mice compared to the control group $(P<0.05$, Fig. 1A). Conversely, DBA/2J mice tend to exhibit severe generalized susceptibility to the virus, typically resulting in death 8 - 10 days after infection [20] (Fig. 1B).

In this analysis, the inflammatory cellular influx in infected mice had begun to emerge by day 2 after $\mathrm{SeV}$ infection. On days 4 and 8 , the total leukocyte count in BALF had increased significantly in both C57BL/6J $(* P<0.05)$ and DBA/2J $(* * * P<$ 0.001) mice compared with the control group. The DBA/2J mice had a significantly higher proportion of macrophages (Control versus DBA/2J ***P $<0.0001$; DBA/2J versus C57BL/6J **P $<0.001$ ) and neutrophils (Control versus DBA/2J ***P<0.0001; $\mathrm{DBA} / 2 \mathrm{~J}$ versus $\mathrm{C} 57 \mathrm{BL} / 6 \mathrm{~J} * * P<0.05)$ as compared to $\mathrm{C} 57 \mathrm{BL} / 6 \mathrm{~J}$ mice and the control group (Fig 1C). The two strains did not show any significant difference in the 
lymphocyte populations. However, on days 4 and 8, C57BL/6J mice had also higher cellular influx of macrophages (Control versus C57BL/6J $* P<0.05$ ), neutrophils (Control versus C57BL/6J *P $<0.05$ ) and lymphocytes (Control versus C57BL/6J $* P<$ 0.005) as compared to the control group (Fig 1C). In addition, on day 14 post infection (p.i.) the cellular influx in $\mathrm{C} 57 \mathrm{BL} / 6 \mathrm{~J}$ mice had declined to almost the same level as that of the control group (Fig. 1C, F). Over all, DBA/2J mice had a 2-fold greater cellular influx than $\mathrm{C} 57 \mathrm{BL} / 6 \mathrm{~J}$ mice $(* * P<0.05)$, consisting mainly of macrophages, neutrophils, and lymphocytes (Control versus C57BL/6J $* P<0.05$; Control versus DBA/2J *** $P<0.0001 ; \mathrm{DBA} / 2 \mathrm{~J}$ versus $\mathrm{C} 57 \mathrm{BL} / 6 \mathrm{~J} * * P<0.001$, Fig. $1 \mathrm{C}$, F). Next, we determined the viral titers from lung tissues of these strains by plaque assay and direct measurement of viral RNA (Fig. 1D, E). Viral titers increased significantly, peaking on day 4 in both strains (Control versus C57BL/6J $* * P<0.005$; Control versus DBA/2J $* * * P<0.0001)$. The viral load remained significantly higher in $\mathrm{DBA} / 2 \mathrm{~J}$ mice $(* P<0.05)$ compared to that of $\mathrm{C} 57 \mathrm{BL} / 6 \mathrm{~J}$ mice. However, C57BL/6J mice demonstrated a considerable increase in viral titer on day 4, which decreased to nearly basal levels by day 8 , and reached an undetectable level by day 14 . This finding was consistent with previous reports of viral clearance between 12-21 days following $\mathrm{SeV}$ infection in resistant mouse strains $[22,23]$. Viral titers in DBA/2J mice correlated with the severity of disease, which consistently suggest that there is indeed a connection between the pulmonary titers and the morphological and clinical characteristics of the infection [22].

Therefore, we investigated the inflammatory dynamics of the pulmonary epithelium by comparing lung histopathological changes after viral infection. Representative sections taken from each group of mice demonstrated the relative degree of pathological change that developed in the lung after infection (Fig. 2A). There was 
little difference between the first histological profile of C57BL/6J mice and the normal morphology of murine lungs on day 2. The airways were free of exudates and the epithelium appeared intact. On days 4 and 8, cell density in the interstitium appeared slightly elevated, although this returned to normal appearance by day 14 . The histological diagnosis most compatible with these observations was slight broncho-bronchiolitis. In contrast, DBA/2J mice had severe lung pathology, with exudates in the alveolar spaces containing a mixture of epithelial cell debris, macrophages, neutrophils and lymphocytes. From days 4 to 8 , the epithelial lining exhibited large areas of deciliation alternating with degeneration, necrosis, desquamation and marked hyperplasia with uneven thickness and cell arrangements. The lamina propria were infiltrated multifocally by numerous macrophages, neutrophils and lymphoid cells with round nuclei, generating the characteristic perivascular cuffing, and this condition was diagnosed as severe necrotizing and purulent broncho-broncholitis with multifocal alveolitis (Fig. 2A). Next, we analyzed pathological scores for the lung sections. Lung lesions were much more severe in DBA/2J mice than in C57BL/6J mice, when compared to the control group on days 4 (Control versus DBA/2J $* * * P<0.001 ; \mathrm{DBA} / 2 \mathrm{~J}$ versus $\mathrm{C} 57 \mathrm{BL} / 6 \mathrm{~J} * * P<0.005$ ), and 8 (Control versus DBA/2J *** $P<0.0001 ; \mathrm{DBA} / 2 \mathrm{~J}$ versus $\mathrm{C} 57 \mathrm{BL} / 6 \mathrm{~J} * * P<0.001$; Control versus C57BL/6J $* P<0.05)$ (Fig. 2B).

\subsection{Kinetics of pro-inflammatory bronchoalveolar lavage fluid cytokines}

Next, we determined the cytokine protein levels in BALF from all groups. $\mathrm{SeV}$ infection appears to induce the majority of the tested BALF cytokines in both strains, with the preponderance reaching peak levels on day 4 or day 8-p.i., as compared to the control group (Fig. 3). We observed the induction of some of the cytokines on day 2 p.i., with the DBA/2J mice showing significantly higher levels of IL-6 and IFN- $\gamma$ 
compared to the C57BL/6J mice $\left({ }^{*} P<0.05\right)$ (Fig. 3), indicating an early immune response in DBA/2J mice. Notably, on day 4 p.i., we observed a distinct and robust response to $\mathrm{SeV}$-induced pneumonia in both strains, although the $\mathrm{DBA} / 2 \mathrm{~J}$ mice produced much higher levels of cytokines, which correlated with the increased levels of lung cellular influx in this strain. Generally, DBA/2J mice had significantly elevated levels of IL-1ß, IL-2, IL-6, IFN- $\gamma$, TNF- $\alpha$ and GM-CSF compared to C57BL/6J, which instead had significantly elevated levels of IL-1 $\alpha$, IL-4, IL-10, IL-12 and G-CSF $(* P<$ 0.05). Furthermore, day 8 p.i. coincided with the time of viral clearance in C57BL/6J mice but severe lung pathology with persistent high viral titer in DBA/2J mice. The levels of these cytokines (IL-1ß, IL-2, IL-6, IFN- $\gamma$, TNF- $\alpha$, GM-CSF) remained steadily and significantly elevated in $\mathrm{DBA} / 2 \mathrm{~J}$ mice $\left({ }^{*} P<0.05\right)$, whereas $\mathrm{C} 57 \mathrm{BL} / 6 \mathrm{~J}$ mice produced only IL-10 and IL-12 $(* P<0.05)$. In addition, we analyzed and compared BALF between C57BL/6J and control mice on day 14 following infection. With the exception of IL-6 and IL-12, the majority of cytokines assayed had returned to normal baseline levels. The timing of this phenomenon coincides with the time at which viral titers were undetectable in this strain (Fig. 1D, E). Taken together, these results indicate that $\mathrm{DBA} / 2 \mathrm{~J}$ mice mount an early response to $\mathrm{SeV}$ infection characterized by the increased production of inflammatory mediators, whereas C57BL/6J mice more tightly regulate the inflammatory immune response.

\subsection{Gene regulation in murine lung after Sendai virus infection}

The mortality typically exhibited by DBA/2J mice occurs when virus-specific adaptive immune response would have developed (Fig. 1B) [20]. Therefore, we assessed the transcriptional regulation of inflammatory cytokine/chemokine and receptor genes at early and late time points following $\mathrm{SeV}$ infection, by generating a comparative transcriptional profile of the lungs of SeV-infected C57BL/6J and DBA/2J 
mice, and uninfected control mice. Using quantitative RT-PCR analysis, we profiled 84 inflammatory cytokine/chemokine and receptor genes. Cluster analysis of the arrays clearly indicated a distinct pattern of responses to $\mathrm{SeV}$-induced pneumonia throughout the course of infection (Fig. 4). DBA/2J mice mounted an early immune response two days after $\mathrm{SeV}$ infection, with the up-regulation of immune regulatory genes that included Ifng, Tnfrsf1a, Tnfrsf1b, Il2rb, Il3, Il5ra, Il11, Scye1, Ccl3, Ccl11, Ccl19, Ccl22, Ccl25 and Cxcl1, as well as other related inflammatory genes such as Abcf1 and C3. However, only Il6ra, Il6st and Cxcl15 were induced in C57BL/6J mice (Fig. 4). Furthermore, on day 4 p.i., coincident with viral replication and the activation of immune responses, the set of genes in these strains that were up- or down-regulated were highly distinct from each other. These data correspond to the cellular influx, viral titers and pro-inflammatory BALF cytokine responses observed on day 4 p.i. (Fig. 1C, D, F, 3). C57BL/6J mounted a robust response on day 4 p.i., with the exclusive up-regulation of a cluster of cytokine/chemokine receptor genes (Fig. 4). The expression of these genes became undetectable on day 8 p.i., with only a limited number of genes (Il1r2, Cxcl13, Cxcr3, Ccl5, Ccr2, Itgam, Cxcl15, Cxcl10, Il6st, Il1b) that were up-regulated in this strain (Fig. 4). These results suggest that C57BL/6J mice have a superior ability to repress $\mathrm{SeV}$ infection, which was reflected in the decrease in viral titer and less severe lung pathology observed in this strain (Fig. 1D, E, 2). These data further, indicated a very steady immune response in $\mathrm{C} 57 \mathrm{BL} / 6 \mathrm{~J}$ mice in response to $\mathrm{SeV}$-induced pneumonia. Conversely, $\mathrm{SeV}$ infection in DBA/2J mice was typified by a consistent pattern of gene regulation on days 2 and 4; however, on day 8 we observed a deviation in the previously up-regulated genes in DBA/2J mice, with an alternate group of genes being up-regulated (Fig. 4). This result indicates a dysregulated immune system in $\mathrm{DBA} / 2 \mathrm{~J}$ mice and correlates with the persistently high 
viral titers and severe lung pathology observed in this strain (Fig. 1D, E, 2). On day 14 p.i., in C57BL/6J mice, Ilr10b, Il15, Tnfrst1a, Cxcl12, Mif and Itgam, were up-regulated, coincident with undetectable levels of viral particles and near normal lung architecture (Fig. 1D, E, 2, 4). This observation is in agreement with earlier reports, which indicated that $\mathrm{SeV}$ infection in resistant strains is characterized by a slight peak in viral titer on days $4-5$, followed by a rapid decline in titer, with virus no longer detectable on days $10-11$ p.i. [12].

Taken together, our analysis revealed that C57BL/6J mice tend to mount an efficient immune response, which enables it to clear the virus, whereas DBA/2J mice mount a strong immune response and succumb to infection with severe lung injury. Therefore, we sought to identify key inflammatory immune regulators in the lungs of these two strains by performing a detailed comparative bioinformatics analysis. We used a $t$-test* $\log 2$ fold-change analysis of gene expression with a cut-off criteria of 10-fold up- or down-regulation, and differences were considered significant at $P<0.05$ based on reliable Ct-values. We detected 56 genes exhibiting differential relative expression levels in $\mathrm{DBA} / 2 \mathrm{~J}$ when compared to $\mathrm{C} 57 \mathrm{BL} / 6 \mathrm{~J}$ mice. In addition, our analysis further revealed 26 and 5 significantly up- and down-regulated genes, respectively $(P<0.05)$ (Table 1$)$. The majority of the consistently up-regulated cytokine/chemokine and receptor genes in $\mathrm{DBA} / 2 \mathrm{~J}$ mice were; $\mathrm{CC}$ family chemokines (Ccl3 (MIP-1A), Ccl11 Ccl19, Ccl22), interleukins (Ifng, Il3, Il11, Il13, Il16, Cx3cl1(Scye1)), CXC family chemokines (Cxcl1, Cxcl10 (IP-10)), chemokine receptors (Ccr8, Ccr9, Xcr1), cytokine receptors (Il2rb, Il5ra, Il6st, Tnfrsf1a, Tnfrsf1b) and other inflammatory-related genes (Abcf1,C3, Crp, Tollip). The down-regulated genes were Ccl5 (RANTES), Itgam, Ltb, Spp1 and Tgfb1. Previously, Ccl3, Cxcl10, Ifng and Il13 have been implicated in the immune response or immunopathology of the disease [24 - 
27].

Interestingly, on day 4 p.i. C57BL/6J responses were modulated exclusively by the up-regulated genes, which included the following: chemokine genes (Ccl2, Ccl4, Ccl5, Ccl6, Ccl7, Ccl8, Ccl9, Ccl12, Ccl17, Ccl24, Cxcl4, Cxcl5, Cxcl9, Cx3cl1), chemokine receptors (Ccr3, Ccr4, Ccr5, Ccr6, Ccr7, Ccr10, Cxcr5), cytokine genes (Il1A, Il1f8, Il1f6, Il4, Il10, IL20, Tnf, Lta, Ltb, Cd40n1g, Tgbf1, Itgam), cytokine receptors (Il1r1, Il2rg, Il8rb) and Casp1, which is an inflammatory response gene (Fig. 4).

Additionally, we found that of all the genes analyzed in this study, gene transcripts that include Ifng, Itgb2, Il1B, Il3, Il10rb, Il11, Il18, Ccl20, Ccl25, Cxcl1, $C x 3 c l, A b f c f 1$ and Bc16 were commonly up-regulated in both strains (Fig. 4). These results depict the scenario of an existing immune pathway by which the two strains could be exerting similar immune responses. However, there were distinct differences between the two strains in the expression of inflammatory mediators triggered by $\mathrm{SeV}$ infection in terms of absolute values, phases, and tissue damage. These differences appear to be associated with the severity and progression of the disease, thereby resulting in the death of the susceptible $\mathrm{DBA} / 2 \mathrm{~J}$ mice, and in the recovery of the resistant C57BL/6J mice (Fig. 1B, 5D).

3.4 The kinetics and role of $C D 4^{+}, C D 8^{+}$and $N K\left(C D 49 b^{+}\right)$T cells in immune response and immunopathology of Sendai virus infection

$\mathrm{T}$ cells play pivotal roles in defending the body from invading pathogens by killing infected cells and providing growth factors to other immune cells. T cells recruited following respiratory viral infection can be either pro-inflammatory or regulatory with the possibility that abnormal recruitment may increase inflammation $[19,28]$. We analyzed immune responses at this early and late phase of the infection focusing on 
CD4+ and CD8 $+\mathrm{T}$ cells and NK T cells in BALF of infected mice. We report that C57BL/6J mice had higher proportions of $\mathrm{CD}^{+}, \mathrm{CD}^{+}$and $\mathrm{NK}\left(\mathrm{CD} 49 \mathrm{~b}^{+}\right) \mathrm{T}$ cells that are required for effective viral clearance compared to DBA/2J mice (Fig. 5A, C). However, the $\mathrm{T}$ cell responses with expression of high levels of IFN- $\gamma$ were earlier in DBA/2J mice than in C57BL/6J mice (Fig. 5B, C). The early high expression levels of IFN- $\gamma$ and lack of well-coordinated T cell responses in DBA/2J mice must have delayed the viral clearance, resulting in the severe lung pathology observed in this strain [22, 23].

\section{Discussion}

The interface between host and pathogen represents an ultimate battleground for survival: the pathogen must secure a niche for replication, whereas the host must limit the pathogen's advance. Thus, upon initial encounter (day 2 p.i.) both strains of mice seem to trigger a similar sequence of defensive events, typically characterized by the activation of tissue-resident macrophages and recruitment of neutrophils (Fig 1C, F). As infection progresses (days 4 and 8 p.i.), signs of extensive cellular proliferation and tissue damage, as well as T-cell-associated processes become apparent (Fig. 1C, 2, 3). These findings support the concept that both strains may elicit both innate and adaptive immune responses that either have the potential to be beneficial for virus control or may cause more extensive immunopathology.

The timing of pulmonary immune response in DBA/2J mice was early and intense, with the expression of several cytokines. The cytokine profile in DBA/2J mice was similar to that observed in primary human alveolar and bronchial epithelial cells or DBA/2J mice infected with the highly pathogenic H5N1 influenza virus $[29,30]$. Furthermore, both infections were shown to be commonly associated with elevated plasma concentrations of IL-6, TNF- $\alpha$, IFN- $\gamma$, CXCL10 (IP-10), CXCL9 (MIG) and 
CCL2 (MCP-1), supporting the link between disease severity and high viral loads with an increased production of pro-inflammatory cytokines.

$\mathrm{SeV}$ is a strong inducer of interferon as well as other cytokines such as IL-2, TNF- $\alpha$, IL-6 and IL-10, whose peaks were observed on days 7-10 p.i., coincident with clearance of the virus from the lungs [31]. We noted the distinct expression of cellular pro-inflammatory mediators in the BALF of these strains. Virus-infected macrophages and dendritic cells, which reside in close proximity to the epithelium, can produce significant amounts of IFNs and TNF- $\alpha$ and in response to $\mathrm{SeV}$ infection [32]. IFN- $\gamma$ promotes innate immune responses by activating macrophages and enhances the TLR-induced production of TNF- $\alpha$, IL-6 and IL-12 [33]. In addition, IFN- $\gamma$ antagonizes the anti-inflammatory effects of IL-10 either by attenuating IL-10 production, thereby inhibiting the TLR-induced Il10 gene expression or by suppressing IL-10 signaling [34]. Here we demonstrate that during acute illness, DBA/2J mice had increased macrophages recruitments and robust IFN- $\gamma$ responses, as demonstrated by high-peak levels of the IFN-stimulated cytokines TNF- $\alpha$ and IL-6, which likely predispose them to more severe tissue injury [35]. The dysregulation of IL-1ß, IL-6 and TNF- $\alpha$ cytokine expression has been implicated in the pathology of several diseases $[36,37]$. Thus, our data are consistent with a role of these cytokines in inducing lung immunopathology [38]. This suggests that the low levels of these cytokines in C57BL/6J mice might have protected them from excessive inflammation and weight loss.

The over induction of IFN- $\gamma$ by infectious pathogens has also been shown to play a role in inhibiting the development of Th2 responses [39]. We consistently found high levels of IFN- $\gamma$ and IL-2, and low levels of IL-4, IL-10 in the BALF of DBA/2J mice, whereas, IL-4 and IL-10 were expressed at higher levels in C57BL/6J 
mice, suggesting that $\mathrm{DBA} / 2 \mathrm{~J}$ mice are either deficient in migrating inflammatory cells or the cells are not producing these cytokines. Interestingly, our data showed that DBA/2J mice exhibited increased influx of neutrophils and macrophages, which we believed to have had a negative effect on $\mathrm{CD} 4^{+}$and $\mathrm{CD} 8^{+} \mathrm{T}$ cells populations in this strain. The decrease proportion of these cells might have lead to ineffective $\mathrm{T}$ cell immune responses, which allows for the rapid replication of the virus, thereby killing other cells that are important for cellular immunity in this strain. This observation suggests in part, that regulation of cellular influx and $\mathrm{T}$ cell cytolytic functional responses following $\mathrm{SeV}$ infection to a certain extent determine susceptibility to the disease.

The Th1 cytokine IL-12 has been linked to reduced severity of SeV-induced bronchiolar inflammation [40]. Furthermore, mice infected with murine cytomegalovirus, respiratory syncytial virus, influenza virus or herpes simplex virus; displayed high level of IL-12 that is critical for early activation of NK cells and the establishment of a Th1 antiviral, immune response [41, 42]. This cytokine form a bridge that triggers the activation of the adaptive immune response and act synergistically with IL-4 to promote T cell response [42]. Therefore, the low levels of these cytokines in $\mathrm{DBA} / 2 \mathrm{~J}$ mice confirm the lack of effective adaptive immune response required for viral clearance.

In acute influenza infection, $\mathrm{CD}^{+} \mathrm{T}$ cells produce high levels of IL-10, which controls excessive inflammation and associated tissue injury. In addition, blocking IL-10 was found to result in enhanced pulmonary inflammation and injury [43]. In our study, high numbers of $\mathrm{CD}^{+}$and $\mathrm{CD}^{+} \mathrm{T}$ cells with the transiently increased expression of IL-10 were observed in C57BL/6J but not DBA/2J mice, suggesting a link between viral clearance and the regulation of the magnitude of inflammation during 
acute viral infection. Our analysis further revealed that chemokine and receptor genes were up-regulated upon $\mathrm{SeV}$ infection, indicating that the expression of these genes is an essential early host response during $\mathrm{SeV}$ infection. This expression of chemokines probably initiated the cellular influx observed during the course of infection, especially in $\mathrm{DBA} / 2 \mathrm{~J}$ mice. This result is consistent with those from other studies of chemokine expression in the lung during respiratory viral infections $[45,46]$. Perhaps one of the most intriguing aspects of our results was the consistent down-regulation of Ccl5, Tgfb1, Spp1, Ltb and Itgam in DBA/2J mice, whereas these genes remained up-regulated in C57BL/6J mice (Table 1). For instance, Ccl5 (RANTES) has been reported to interact with Ccr5, and provide anti-apoptotic signals for macrophage survival during $\mathrm{SeV}$ infection, and accelerate the recruitment of memory $\mathrm{CD} 8^{+} \mathrm{T}$ cells to the lung airways during viral infection [47, 48]. Furthermore, Itgam, Tgfb1, Ltb and Spp1 play key roles in inflammation, macrophage or T-cell activation, and the initiation of adaptive immune responses in viral infections [49]. The down-regulation of these genes in DBA/2J mice, might account for the decreased recruitment of $\mathrm{T}$ cells subsets observed in this strain, thereby affecting their ability to inhibit the cell-cell infectious process leading to excessive airway inflammation.

Further, we report the up-regulation of Ccl1, Ccl2, Ccl4, Ccl5, Ccl6, Ccl7, Ccl12, Ccr2, Ccr3, Ccr4, Ccr5, Ccr6 and Ccr10 gene transcripts in C57BL/6J mice, and we envisaged that these genes could play essential roles in protective immunity against respiratory viral infections. The severity of SeV infection may be linked to the extent of plasma leakage as a result of dysregulation of these proteins or genes such as IL-2, IL-6, TNF- $\alpha$, INF- $\gamma$, GM-CSF, Il18, Ccl2, Ccl3, Ccl5, Ccl7 and Ccr2, which have been reported to play a role in vascular permeability in addition to their regulatory functions in inflammatory responses [36,45]. Therefore, we postulated that the 
regulation of these genes might be linked to the severe hypoxemia observed in DBA/2J mice.

Finally, we herein report that the deleterious lung pathology seen in DBA/2J mice is in part due to hypercytokinemia (cytokine storm) because of an over-reaction of the immune system that became detrimental to the host. A similar conclusion was drawn in a recent study with influenza A virus infection in mice [50]. Nonetheless, our data emphasize the overall complexity of the processes involved, which can be attributed to the participation of many differentially expressed gene products in the anti-inflammatory regulatory circuits. Thus, our study provides information on the molecular framework leading to either protective immunity or severe disease and death in respiratory viral infections (Fig. 5D). For these reasons, these animal models of immune regulation and enhancement allow for a deeper understanding of the role of specific immune mediators in respiratory viral disease, assist in vaccine design, and indicate which immunomodulatory therapy might be helpful to children with acute bronchiolitis.

5. Acknowledgements: We thank Prof. H. Iwai, Rakuno Gakuen University, for providing the stock of $\mathrm{SeV}, \mathrm{MN}$ strain. SAY was supported by a study fellowship awarded by the Ministry of Education, Culture, Sports, Science and Technology, Japan. This work was supported in part by the Global COE Program, 'Establishment of International Collaboration Centers for Zoonosis Control' from the Japanese Society for the Promotion of Science and Ministry of Education, Culture, Sports, Science and Technology, Japan. 


\section{References}

[1] B.G. Williams, E. Gouws, C. Boschi-Pinto, J. Bryce, C. Dye. Estimates of world-wide distribution of child deaths from acute respiratory infections. Lancet Infect Dis 2 (2002) 25-32.

[2] R. M. Chanock, B. R. Murphy, P. L. Collins, in: D. M. Knipe, P. M. Howley, D. E. Griffin, R. A. Lamb, M. A. Martin, B. Roizman, S. E. Strauss (Eds), Fields Virology, Lippincott, Williams, \& Wilkins, Philadelphia, 2001, pp. 1341-1379.

[3] M.D. de Jong, C.P. Simmons, T.T. Thanh, V.M. Hien, G.J. Smith, T.N. Chau, D.M. Hoang, N.V. Chau, T.H. Khanh, V.C. Dong, P.T. Qui, B.V. Cam, Q. Ha do, Y. Guan, J.S. Peiris, N.T. Chinh, T.T Hien, J. Farrar. Fatal outcome of human influenza a (H5N1) is associated with high viral load and hypercytokinemia. Nat Med 12 (2006) 1203-1207. [4] J.E Gern, G.D. Brooks, P. Meyer, A. Chang, K. Shen, M.D. Evans, C. Tisler, D. Dasilva, K.A. Roberg, L.D Mikus, L.A. Rosenthal, C.J. Kirk, P.A. Shult, A. Bhattacharya, Z. Li, R. Gangnon, R.F. Jr Lemanske. Bidirectional interactions between viral respiratory illnesses and cytokine responses in the first year of life. J Allergy Clin Immunol 117 (2006) 72-78.

[5] F.R. Laham, V. Israele, J.M. Casellas, A.M, Garcia, C.M. Lac Prugent, S.J. Hoffman, D. Hauer, B. Thumar, M.I Name, A. Pascual, N. Taratutto, M.T. Ishida, M. Balduzzi, M. Maccarone, S. Jackli, R. Passarino, R.A. Gaivironsky, R.A. Karron, N.R. Polack, F.P. Polack. Differential production of inflammatory cytokines in primary infection with human metapneumovirus and with other common respiratory viruses of infancy. J Infect Dis 189 (2004) 2047-2056.

[6] G.A. Melendi, F.R. Laham, A.C. Monsalvo, J.M. Casellas, V. Israele, N.R. Polack, S.R. Kleeberger, F.P. Polack. Cytokine profiles in the respiratory tract during primary 
infection with human metapneumovirus, respiratory syncytial virus, or influenza virus in infants. Pediatrics 120 (2007) e410-415.

[7] W.L. Gorman, D.S. Gill, R.A. Scroggs, A. Portner. The hemagglutinin neuraminidase glycoproteins of human parainfluenza virus type 1 and sendai virus have high structure-function similarity with limited antigenic cross-reactivity. Virology 175 (1990) 211-221.

[8] D. Lyn, D.S. Gill, R.A. Scroggs, A. Portner. The nucleoproteins of human parainfluenza virus type 1 and sendai virus share amino acid sequences and antigenic and structural determinants. J Gen Virol 72 (1991) 983-987.

[9] M.H. Skiadopoulos, S.R. Surman, J.M. Riggs, W.R. Elkins, M. St Claire, M. Nishio, D. Garcin, D. Kolakofsky, P.L. Collins, B.R. Murphy. Sendai virus, a murine parainfluenza virus type 1, replicates to a level similar to human piv1 in the upper and lower respiratory tract of african green monkeys and chimpanzees. Virology 297 (2002) 153-160.

[10] J.L Hurwitz. Development of recombinant sendai virus vaccines for prevention of human parainfluenza and respiratory syncytial virus infections. Pediatr Infect Dis J 27 (2008) S126-128.

[11] M. Boeckh. The challenge of respiratory virus infections in hematopoietic cell transplant recipients. Br J Haematol 143 (2008) 455-467.

[12] P. Faisca, D. Desmecht. Sendai virus, the mouse parainfluenza type 1: A longstanding pathogen that remains up-to-date. Res Vet Sci 82(2007) 115-125.

[13] P.L. Collins, B.S. Graham. Viral and host factors in human respiratory syncytial virus pathogenesis. J Virol 82 (2008) 2040-2055.

[14] P.J. Openshaw, J.S Tregoning. Immune responses and disease enhancement during respiratory syncytial virus infection. Clin Microbiol Rev 18 (2005) 541-555. 
[15] H.A. Haeberle, W.A. Kuziel, H.J. Dieterich, A. Casola, Z. Gatalica, R.P. Garofalo. Inducible expression of inflammatory chemokines in respiratory syncytial virusinfected mice: role of MIP-1alpha in lung pathology. J Virol 75 (2001) 878-890.

[16] P.S. McNamara, B.F. Flanagan, C.A. Hart, R.L. Smyth. Production of chemokines in the lungs of infants with severe respiratory syncytial virus bronchiolitis. J Infect Dis 191 (2005) 1225-1232.

[17] F.J. Culley, A.M. Pennycook, J.S. Tregoning, J.S. Dodd, G. Walzl, T.N. Wells, T. Hussell, P.J. Openshaw. Role of CCL5 (RANTES) in viral lung disease. J Virol 80 (2006) 8151-8157.

[18] V.G. Amanatidou, S. Sourvinos, A. Apostolakis, A. Tsilimigaki, D. A. Spandidos. $\mathrm{T} 280 \mathrm{M}$ variation of the $\mathrm{CX} 3 \mathrm{C}$ receptor gene is associated with increased risk for severe respiratory syncytial virus bronchiolitis. Pediatr. Infect. Dis. J. 25 (2006) 410-414.

[19] J.S. Tregoning, P.K. Pribul, A.M.J. Pennycook, T. Hussell, B. Wang, N. Lukacs, J. Schwarze, F.J. Culley, P.J. Openshaw. The chemokine MIP1a/CCL3 determines pathology in primary RSV Infection by regulating the balance of $\mathrm{T}$ cell populations in the murine lung. PLoS ONE 5 (2010) e9381

[20] A.Y. Simon, K. Moritoh, D. Torigoe, A. Asano, N. Sasaki, T. Agui. Multigenic control of resistance to sendai virus infection in mice. Infect Genet Evol 9 (2009) 1253-1259.

[21] P. Faisca, D.B. Anh, D.J. Desmecht. Sendai virus-induced alterations in lung structure/function correlate with viral loads and reveal a wide resistance/susceptibility spectrum among mouse strains. Am J Physiol Lung Cell Mol Physiol 289 (2005) L777-787. 
[22] S. Hou, P.C. Doherty, M. Zijlstra, R. Jaenisch, J.M. Katz. Delayed clearance of sendai virus in mice lacking class I MHC-restricted CD8+ T cells. J Immunol 149 (1992) 1319-1325.

[23] W. Zhong, A.D. Roberts, D.L. Woodland. Antibody-independent antiviral function of memory CD4+ $\mathrm{T}$ cells in vivo requires regulatory signals from $\mathrm{CD} 8+$ effector $\mathrm{T}$ cells. J Immunol 167 (2001) 1379-1386.

[24] E.Y. Kim, J.T. Battaile, A.C. Patel, Y. You, E. Agapov, M.H. Grayson, L.A. Benoit, D.E. Byers, Y. Alevy, J. Tucker, S. Swanson, R. Tidwell, J.W. Tyner, J.D. Morton, M. Castro, D. Polineni, G.A. Patterson, R.A. Schwendener, J.D. Allard, G. Peltz, M.J. Holtzman. Persistent activation of an innate immune response translates respiratory viral infection into chronic lung disease. Nat Med 14 (2008) 633-640.

[25] S. Matikainen, J. Pirhonen, M. Miettinen, A. Lehtonen, C. Govenius-Vintola, T. Sareneva, I. Julkunen. Influenza A and sendai viruses induce differential chemokine gene expression and transcription factor activation in human macrophages. Virology $276(2000) 138-147$.

[26] C.P. Elco, J.M. Guenther, B.R. Williams, G.C. Sen. Analysis of genes induced by sendai virus infection of mutant cell lines reveals essential roles of interferon regulatory factor 3, NF-kappaB, and interferon but not toll-like receptor 3. J Virol 79 (2005) 3920-3929.

[27] X. Cai, W.L. Castleman. Increased IFN-gamma protein in bronchoalveolar lavage fluid of anti-IP-10 antibody-treated F344 rats following sendai viral infection. J Interferon Cytokine Res 22 (2002) 1175-1179.

[28] J.S. Tregoning, Y. Yamaguchi, J. Harker, B. Wang, P.J. Openshaw. The role of T cells in the enhancement of respiratory syncytial virus infection severity during adult reinfection of neonatally sensitized mice. J Virol 82 (2008) 4115-4124. 
[29] A.C. Boon, J. deBeauchamp, A. Hollmann, J. Luke, M. Kotb, S. Rowe, D. Finkelstein, G. Neale, L. Lu, R.W. Williams RW, R.J. Webby. Host genetic variation affects resistance to infection with a highly pathogenic H5N1 influenza a virus in mice. $\mathrm{J}$ Virol 83 (2009) 10417-10426.

[30] M.C. Chan, C.Y. Cheung, W.H. Chui, S.W. Tsao, J.M. Nicholls, Y.O. Chan, R.W. Chan, H.T. Long, L.L. Poon, Y. Guan, J.S. Peiris. Pro-inflammatory cytokine responses induced by influenza a (H5N1) viruses in primary human alveolar and bronchial epithelial cells. Respir Res 5 (2005) 135.

[31] X.Y. Mo, S.R. Sarawar, P.C. Doherty. Induction of cytokines in mice with parainfluenza pneumonia. J Virol 69 (1995) 1288-1291.

[32] V. Veckman, P. Osterlund, R. Fagerlund, K. Melen, S. Matikainen, I. Julkunen. TNF-alpha and IFN-alpha enhance influenza-a-virus-induced chemokine gene expression in human A549 lung epithelial cells. Virology 345 (2006) 96-104.

[33] X. Hu, L.B. Ivashkiv. Cross-regulation of signaling pathways by interferon-gamma: Implications for immune responses and autoimmune diseases. Immunity 31 (2009) 539-550.

[34] M.J. Cameron, L. Ran, L. Xu, A. Danesh, J.F. Bermejo-Martin, C.M. Cameron, M.P. Muller, W.L. Gold, S.E. Richardson, S.M. Poutanen, B.M. Willey, M.E. DeVries, Y. Fang, C. Seneviratne, S.E. Bosinger, D. Persad, P. Wilkinson, L.D. Greller, R. Somogyi, A. Humar, S. Keshavjee, M. Louie, M.B. Loeb, J. Brunton, A.J McGeer; Canadian SARS Research Network, D.J. Kelvin. Interferon-mediated immunopathological events are associated with atypical innate and adaptive immune responses in patients with severe acute respiratory syndrome. J Virol 81 (2007) 8692-8706. 
[35] C.Y Cheung, L.L. Poon, A.S. Lau, W. Luk, Y.L. Lau, K.F. Shortridge, S. Gordon, Y. Guan, J.S. Peiris. Induction of pro-inflammatory cytokines in human macrophages by influenza a (H5N1) viruses: A mechanism for the unusual severity of human disease? Lancet 360 (2002) 1831-1837.

[36] K.J. Szretter, S. Gangappa, X. Lu, C. Smith, W.J. Shieh, S.R. Zaki, S. Sambhara, T.M. Tumpey, J.M. Katz. Role of host cytokine responses in the pathogenesis of avian H5N1 influenza viruses in mice. J Virol 81 (2007) 2736-2744.

[37] A.M. Akk, P.M. Simmons, H.W. Chan, E. Agapov, M.J. Holtzman, M.H. Grayson, C.T. Pham. Dipeptidyl peptidase i-dependent neutrophil recruitment modulates the inflammatory response to sendai virus infection. J Immunol 180 (2008) 3535-3542.

[38] G. Wohlleben, K.J. Erb. The absence of IFN-gamma leads to increased TH2 responses after influenza a virus infection characterized by an increase in CD4+ but not CD8+ T cells producing IL-4 or IL-5 in the lung. Immunol Lett 95 (2004) 161-166.

[39] A.E. Stone, S. Giguere, W.L. Castleman. IL-12 reduces the severity of sendai virus-induced bronchiolar inflammation and remodeling. Cytokine 24 (2003) 103-113.

[40] J.M. Monteiro, C. Harvey, G. Trinchieri. Role of interleukin-12 in primary influenza virus infection. J Virol 72 (1998) 4825-4831.

[41] L. Romani, P. Puccetti, F. Bistoni. Interleukin-12 in infectious diseases. Clin Microbiol Rev 10 (1997) 611-636.

[42] X.Y. Mo, M.Y. Sangster, R.A. Tripp, P.C. Doherty. Modification of the sendai virus-specific antibody and CD8+ T-cell responses in mice homozygous for disruption of the interleukin-4 gene. J Virol 71 (1997) 2518-2521.

[43] J. Sun, R. Madan, C.L. Karp, T.J. Braciale. Effector T cells control lung inflammation during acute influenza virus infection by producing IL-10. Nat Med 15 (2009) 277-284. 
[44] A.L. Miller, T.L. Bowlin, N.W. Lukacs. Respiratory syncytial virus-induced chemokine production: Linking viral replication to chemokine production in vitro and in vivo. J Infect Dis 189 (2004) 1419-1430.

[45] Y. Zhang, B.A. Luxon, A. Casola, R.P. Garofalo, M. Jamaluddin, A.R. Brasier. Expression of respiratory syncytial virus-induced chemokine gene networks in lower airway epithelial cells revealed by cDNA microarrays. J Virol 75 (2001) 9044-9058.

[46] J. E. Kohlmeier, S.C. Miller, J. Smith, B. Lu, C. Gerard, T. Cookenham, A.D. Roberts, D.L Woodland. The chemokine receptor Ccr5 plays a key role in the early memory CD8+ T cell response to respiratory virus infections. Immunity 29 (2008) 101-113.

[47] J.W. Tyner, O. Uchida, N. Kajiwara, E.Y. Kim, A.C. Patel, M.P. O'Sullivan, M.J. Walter, R.A. Schwendener, D.N. Cook, T.M. Danoff, M.J. Holtzman. Ccl5-Ccr5 interaction provides antiapoptotic signals for macrophage survival during viral infection. Nat Med 11 (2005) 1180-1187.

[48] T.S. Kim, T.J. Braciale. Respiratory dendritic cell subsets differ in their capacity to support the induction of virus-specific cytotoxic CD8+ T cell responses. PLoS One 4(2009) e4204.

[49] J. Chen, M.M. Ng, J.J. Chu. Molecular profiling of T-helper immune genes during dengue virus infection. Virol J 5 (2008) 165.

[50] R. Alberts, B. Srivastava, H. Wu, N. Viegas, R. Geffers, F. Klawonn, N. Novoselova, T.Z. do Valle, J.J. Panthier, K. Schughart. Gene expression changes in the host response between resistant and susceptible inbred mouse strains after influenza A infection. Microbes Infect 12 (2010) 309-18

\subsection{Legends}


Figure 1. Kinetics of immune response in C57BL6/J, DBA2/J and control mouse groups following Sendai virus infection. Mice were infected intranasally and monitored for a period 14 days, with a median tissue culture infectious dose $\left(10^{3}\right.$ $\mathrm{TCID}_{50}$ ) of $\mathrm{SeV}$. Control mice were mock challenged with PBS and for the determination of virulence; three mice from each group as well as the control were weighed daily. (A) Body weight changes in each group, C57BL/6J (black squares), DBA/2J (grey squares) and control (open triangles) mice ( $n=4-5$ per group), following inoculation with SeV or PBS. (B) Survival curves of mouse groups. On days 2, 4, 8 and 14 following inoculation with $\mathrm{SeV}$ or PBS, mice were sacrificed and their lungs were lavaged. (C) Total cellular composition and differential counts of the BALF from C57BL/6J (black bars), DBA/2J (grey bars) and control (open bars) mice ( $n=4-5$ per group at indicated time points). Total cell counts on both days 4 and 8 p.i.: Control versus C57BL/6J, $* P<0.05$; Control versus DBA/2J, ***P $<0.001 ; \mathrm{C} 57 \mathrm{BL} / 6 \mathrm{~J}$ versus versus $\mathrm{DBA} / 2 \mathrm{~J},{ }^{* *} P<0.05$. Data are presented as mean total leucocytes and mean absolute values of differential counts; Macrophages (Control versus DBA/2J ***P< 0.0001; DBA/2J versus C57BL/6J **P $<0.001$; Control versus C57BL/6J mice $* P<$ 0.05); Neutrophils (Control versus DBA/2J $* * * P<0.0001$; DBA/2J versus C57BL/6J ${ }^{* *} P<0.05$; Control versus $\mathrm{C} 57 \mathrm{BL} / 6 \mathrm{~J}$ mice $* P<0.05$ ), and Lymphocytes (Control versus DBA $/ 2 \mathrm{~J} * * P<0.001$; Control versus $\mathrm{C} 57 \mathrm{BL} / 6 \mathrm{~J}$ mice $* P<0.005), \pm \mathrm{SEM}$. (D-E) The pulmonary kinetics of lung viral replication of $\mathrm{SeV}$ infected mice. The viral replication levels in the lung tissue of all groups after infection were determined by plaque assay on LLC-MK2 cells and real-time quantitative RT-PCR. Lung viral titers of all mouse groups on days 2, 4, 8 and 14 following SeV infection. (D) Plaque assay and (E) qRT-PCR analysis of lung viral titers after infection with $\mathrm{SeV}$ or PBS. Titers are expressed in $\log _{10}$ viral copies or gram per lung tissue: Control versus DBA/2J, 
***P $<0.0001$; Control versus C57BL/6J, ${ }^{* *} P<0.005$; DBA $/ 2 \mathrm{~J}$ versus C57BL/6J, ${ }^{*} P<$

0.05. (F) Photomicrograph representation of cytospin slides ( $\times 20$ magnification $)$ of the pulmonary cellular influx from the BALF of all mouse groups at the indicated time points; Giemsa staining, Bar $=100 \mu \mathrm{m}$.

Figure 2. Lung pathology is more severe in DBA/2J than in C57BL/6J following Sendai virus infection. (A) Histopathology of representative lung sections taken at indicated time points following $\mathrm{SeV}$ infection. Lung sections of C57BL/6J (panel A D), DBA/2J (panel E - G) and control mice (panel H) at $\times 10$ magnification. DBA/2J mice had exudates in the alveolar spaces that contain a mixture of epithelial cell debris, neutrophils, lymphocytes and morphologically altered macrophages (black arrows). From days 4 to 8 p.i. (panel F-G) the epithelial lining exhibited large areas of deciliation alternating with degeneration, necrosis, desquamation and marked hyperplasia with uneven thickness and cell arrangements (blue arrows). On day 2 p.i., the lungs of C57BL/6J mice (panel A) had no exudates in the airways and their epithelium appeared generally intact. All alveolar spaces were empty, with the exception of a small number of macrophages, neutrophils and lymphoid cells, the density of which was comparable to that observed in the normal control lung. However, on days 4 and 8 p.i. the interstitial cell density appeared slightly elevated (panel B - C) (black arrows), although this returned to normal by day 14 p.i. (panel D). (B) Histogram showing the pathological index scores at representing the degree of lung lesions by H\&E stain in each group at indicated time points. The degree of distribution and severity of inflammatory infiltrates/structural alterations were examined around the small airways and adjacent blood vessels and changes were graded on a scale of 1- 6 (Normal: 1; slight/mild: 2; moderately severe: 4; severe/high: 6). Results are expressed as the 
mean values of the pathological index in the experimental groups. Error bars, $1 \mathrm{SE}$. Lung sections were stained with H\&E for histological evaluation, Bar $=100 \mu \mathrm{m}$.

Figure 3. Sendai virus infection induces high levels of lung pro-inflammatory cytokines that are either beneficial or detrimental to the host. Pulmonary cytokine (IL-1 $\alpha$, IL-1ß, IL-2, IL-4, IL-6, IL-10, IL-12, IL-17 $\alpha$, IFN- $\gamma$, TNF- $\alpha$, G-CSF and GM-CSF) levels were determined in the BALF of C57BL/6J (black bars), DBA/2J (ash-grey bars) and control (open bars) mice ( $n=4$ per group) following inoculation with SeV or PBS. BALF samples were collected on days 2, 4, 8 and 14, and cytokine levels were determined in duplicates using the mouse panel of the Multi-Analyte ELISArray profiler. Data are expressed as the mean \pm SEM of 4 mice measured in $\mathrm{pg} / \mathrm{ml}$ at each time point. Students t-test was use to determine the statistical differences between $\mathrm{C} 57 \mathrm{BL} / 6 \mathrm{~J}$ and $\mathrm{DBA} / 2 \mathrm{~J}$ mice, $(* P<0.05)$ and control versus C57BL/6J, $\left({ }^{*} P<0.05\right)$ on day 14.

Figure 4. Sendai virus infection causes changes in cytokine/chemokine gene expression in the lungs of DBA/2J and C57BL/6J mice. Cluster analysis showing a heat map of mouse inflammatory cytokine/chemokine and receptor genes regulated in the lungs of $\mathrm{C} 57 \mathrm{BL} / 6 \mathrm{~J}, \mathrm{DBA} / 2 \mathrm{~J}$ and control mice. $\mathrm{DBA} / 2 \mathrm{~J}$ mice mounted a rapid and intense inflammatory, immune response, with significant up-regulation of cytokine/chemokine and receptor genes in two successive waves from days $2-4$, and 8 after infection. In contrast, clusters of immune responsive genes were exclusively up regulated in $\mathrm{C} 57 \mathrm{BL} / 6 \mathrm{~J}$ mice on day 4 . A $2 \mathrm{D}$ gene tree was generated using the average linkage clustering heat map method. Genes with a significant fold change $(P$ $<0.001)$ are shown. Each row represents the lungs of mice from each group at the 
indicated time points, and the hierarchical structure of the intervals and infection response are illustrated as a dendrogram while the fold change values are color coded with green for down-regulated genes, black for average or unregulated genes and red for up-regulated genes.

Figure 5. Differential antigen-specific cellular immune response required for viral clearance in infected mice. The dynamics of changes in lung lavage cells were assessed by flow cytometry for the proportions of $\mathrm{CD} 4+, \mathrm{CD} 8+$ and $\mathrm{NK} \mathrm{T}$ cells on days 2, 4, 8 and 14 after $\mathrm{SeV}$ infection. Antigen-specific IFN- $\gamma$ producing cells were measured by intracellular staining. Gates based on isotype control staining were used to identify the percentage of cells bearing markers of a specific linage and numbers in plots indicate percent cells in each quadrant. (A) Double staining of $\mathrm{CD}^{+} / \mathrm{CD}^{+} \mathrm{T}$ cells, (B) CD4 ${ }^{+} \mathrm{T}$ cell and IFN- $\gamma$ or $\mathrm{CD}^{+} \mathrm{T}$ cell and IFN- $\gamma,(\mathrm{C}) \mathrm{NK}\left(\mathrm{C} 49 \mathrm{~b}^{+}\right) \mathrm{T}$ cells and IFN- $\gamma$. The profiles provided are representatives of one of two separate experiments for both mouse strains. (D) An overview of the sequence of immune events leading to viral clearance or severe lung immunopathology following $\mathrm{SeV}$ infection in mice.

Table 1. Log2 fold-changes in the gene expression of inflammatory cytokine/chemokine and receptors, observed in DBA/2J compared to C57BL/6 J mice throughout the course of infection. Relative changes in gene expression between these mice were calculated using the $\Delta \Delta \mathrm{Ct}$ (cycle threshold) method at all indicated time points. The average of the cycle numbers of the five housekeeping genes Gusb, Hprt1, Hsp90ab1, Gapdh, and Actb was used to normalize the expression between samples. The expression data is presented as 10 -fold changes or more in up- or down-regulation. 
Overall changes in gene expression were analyzed by $t$-test*. Changes were considered significant at $P<0.05$, based on reliable $\mathrm{Ct}$ values.

\section{END}


(A)

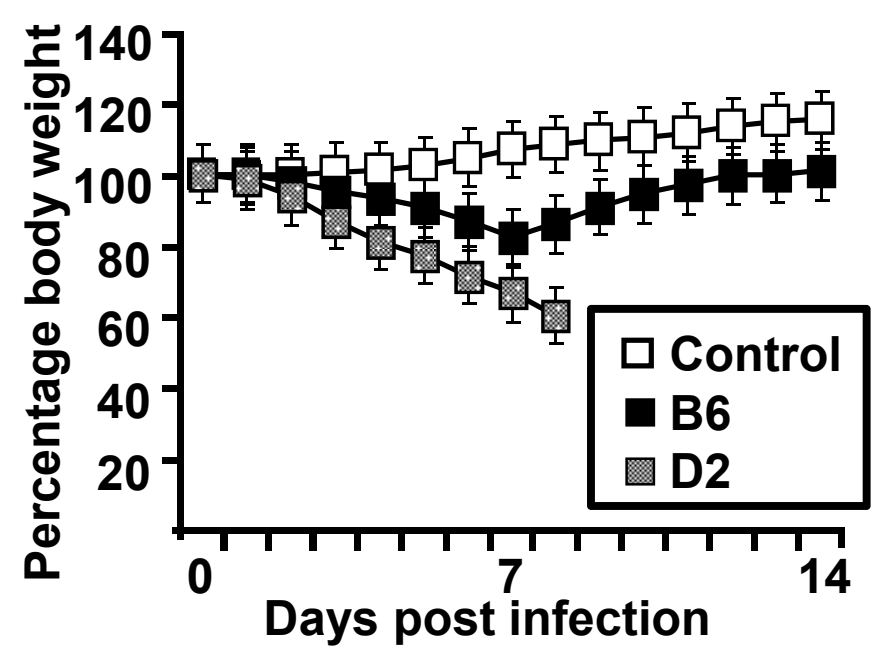

(B)

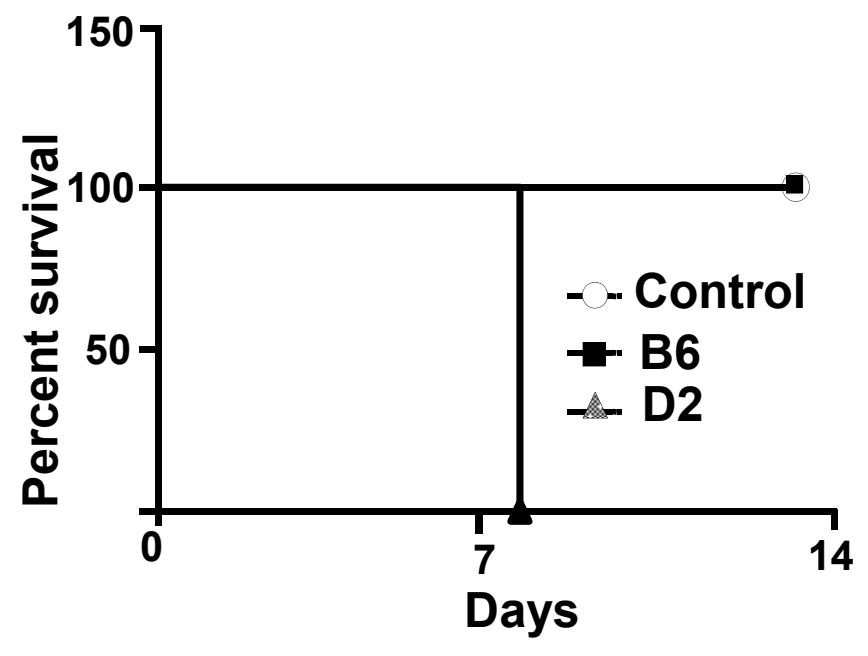

(C)

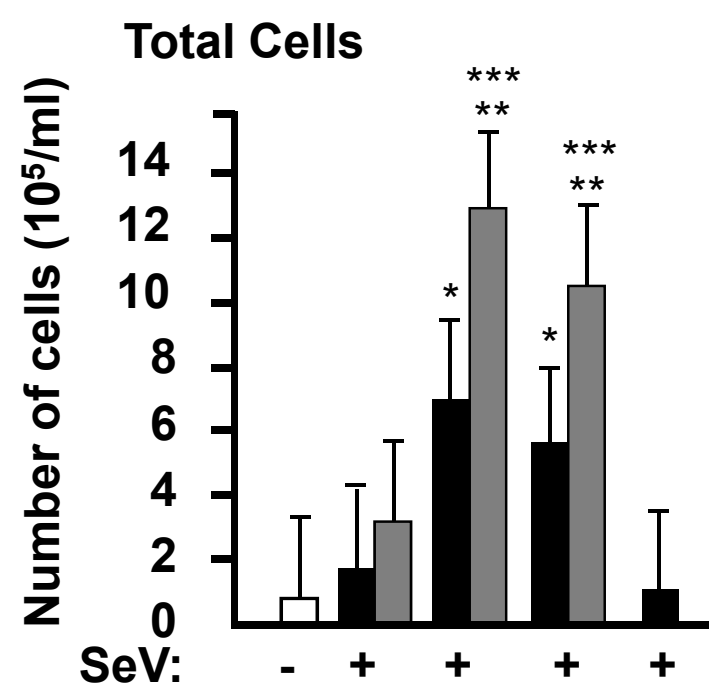

$\begin{array}{llllll}\text { Day: } & 0 & 2 & 4 & 8 & 14\end{array}$

Neutrophils

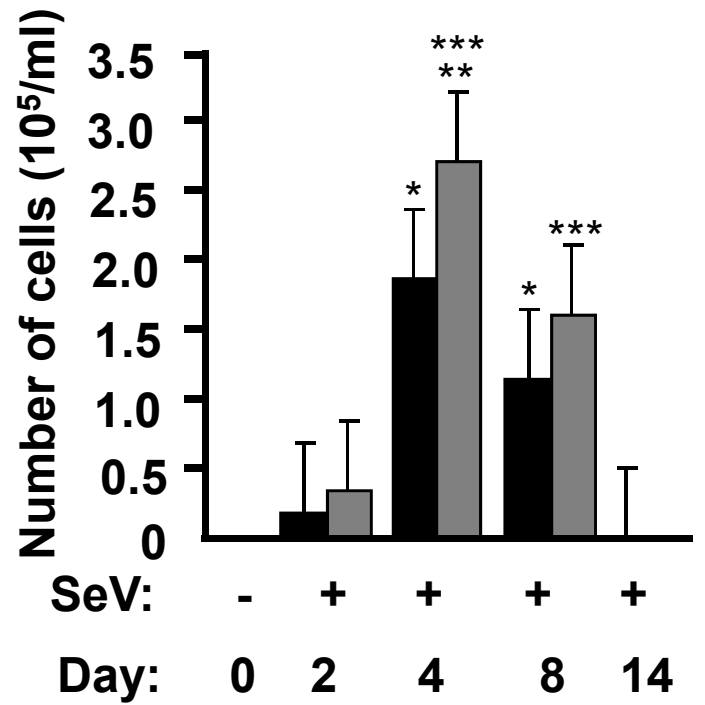

Macrophages
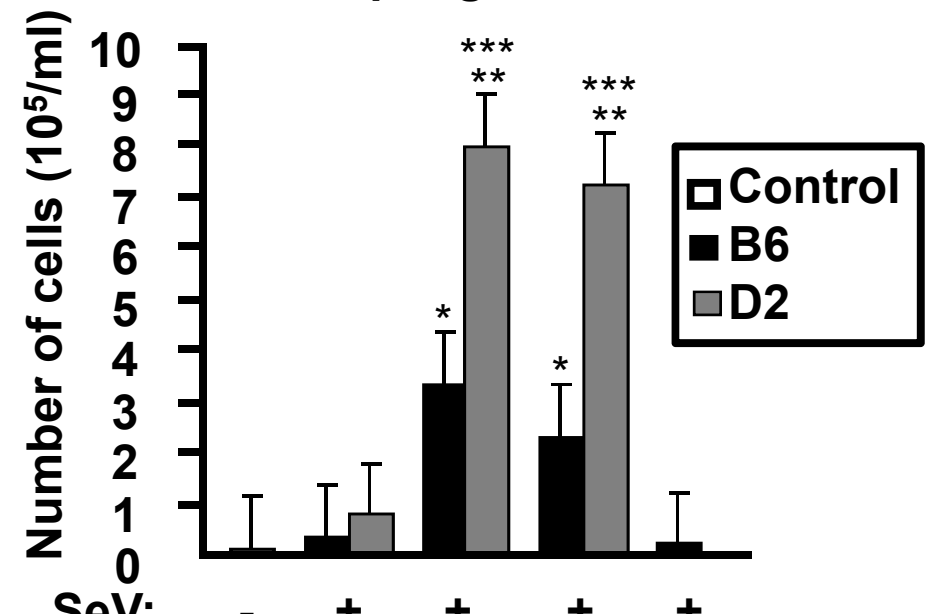

Day: $\begin{array}{llllll}0 & 2 & 4 & 8 & 14\end{array}$

Lymphocytes

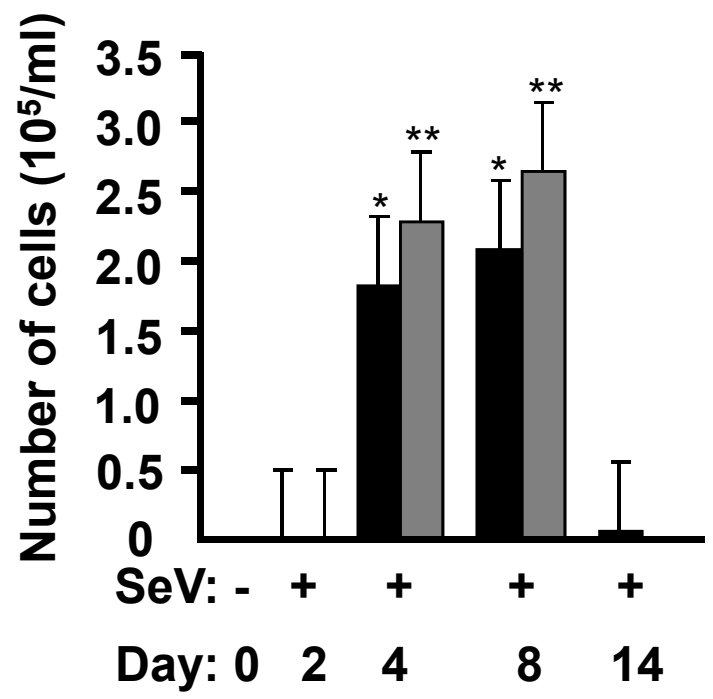


(D)

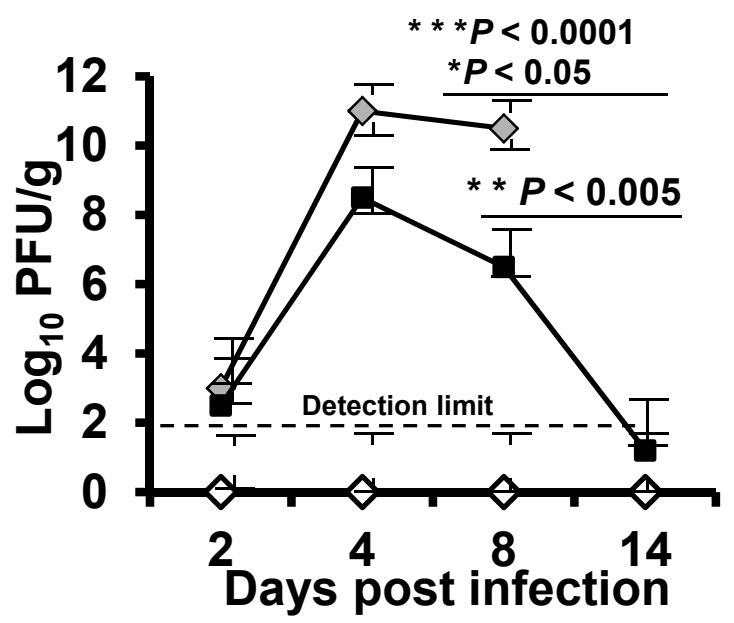

(E)

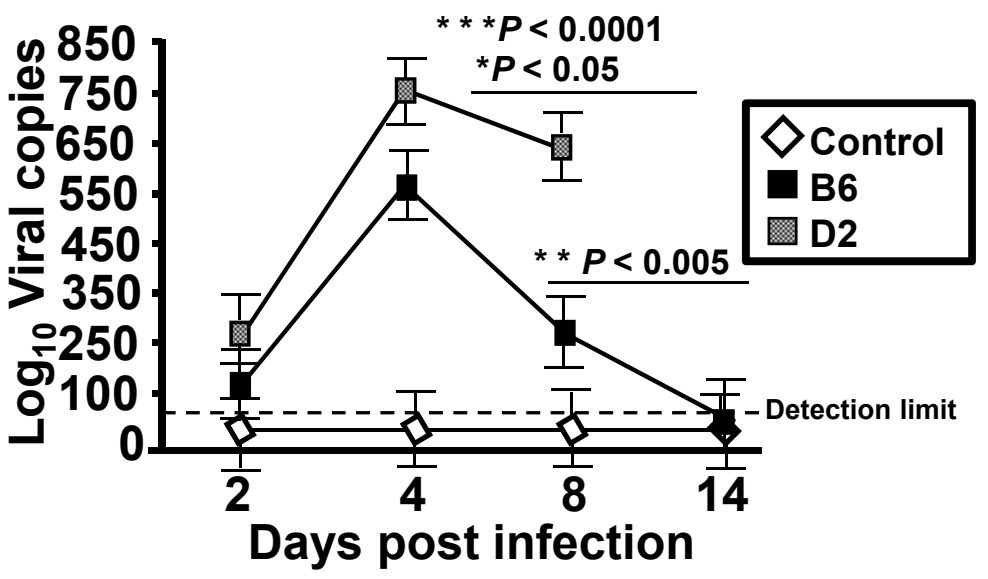

(F)
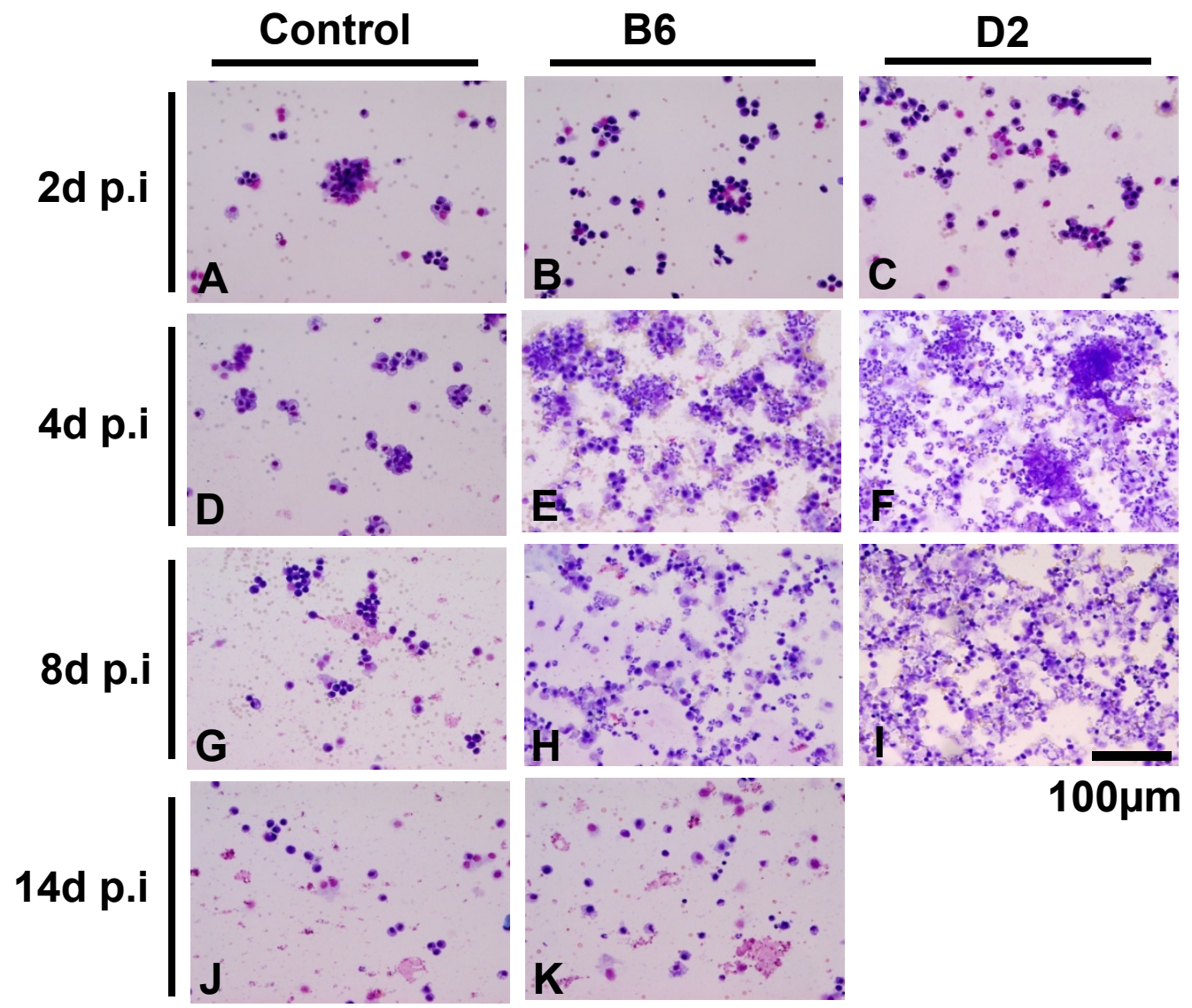

$100 \mu \mathrm{m}$ 
(A)

B6

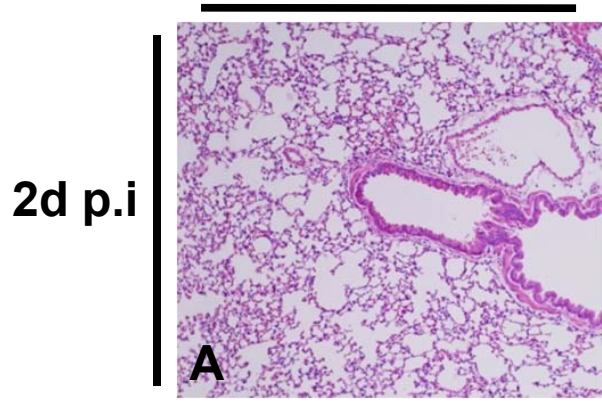

4d p.i

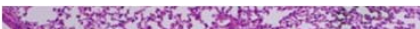

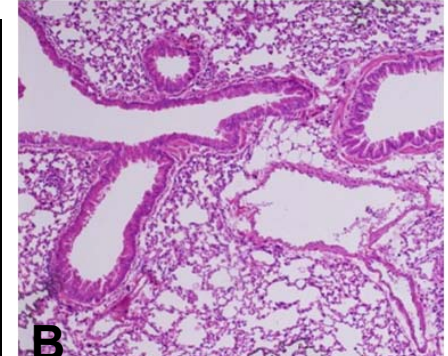

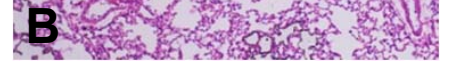
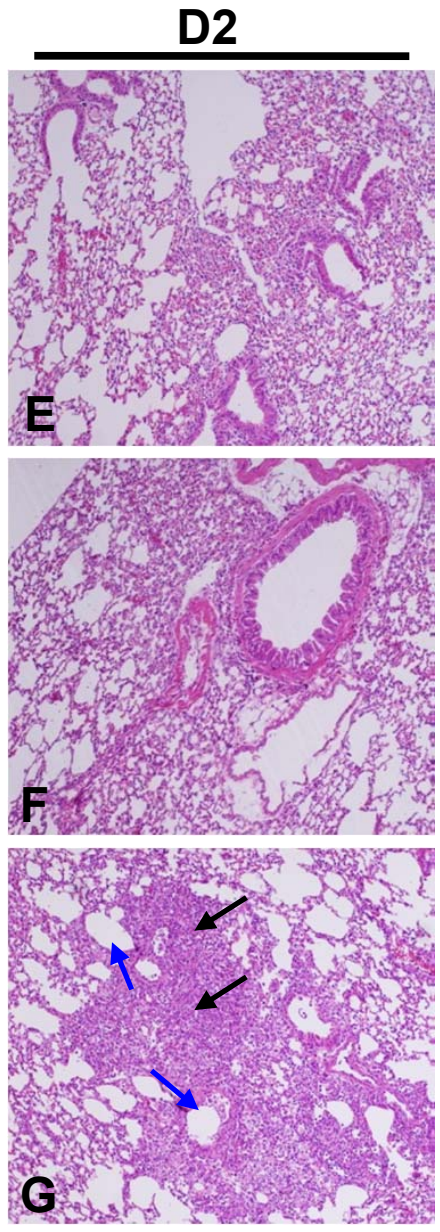

14d p.i $\mid \begin{array}{lll} \\ 0 \\ D\end{array}$

8d p.i

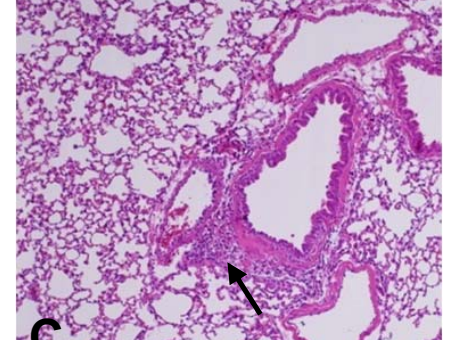

C

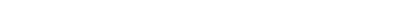

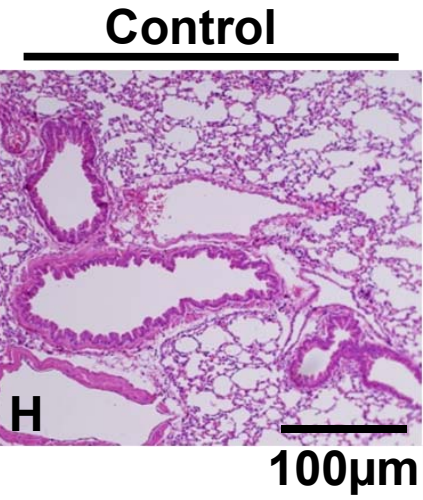

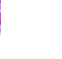

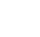

(B)

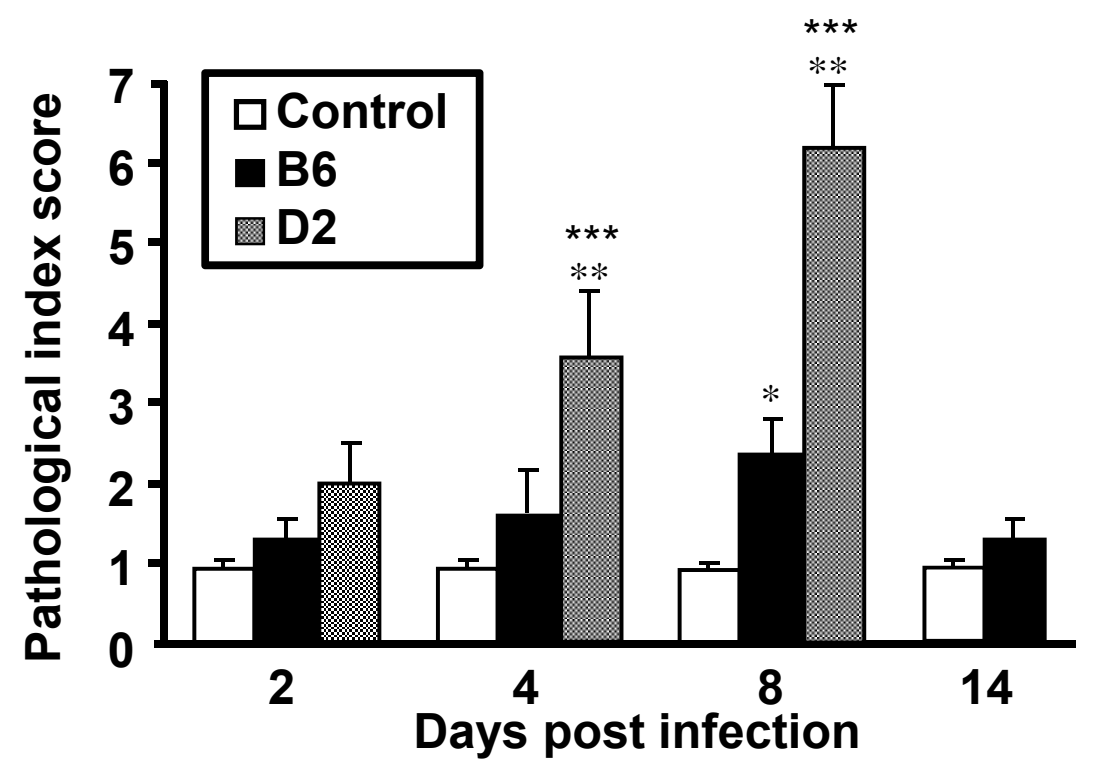


FIG 3

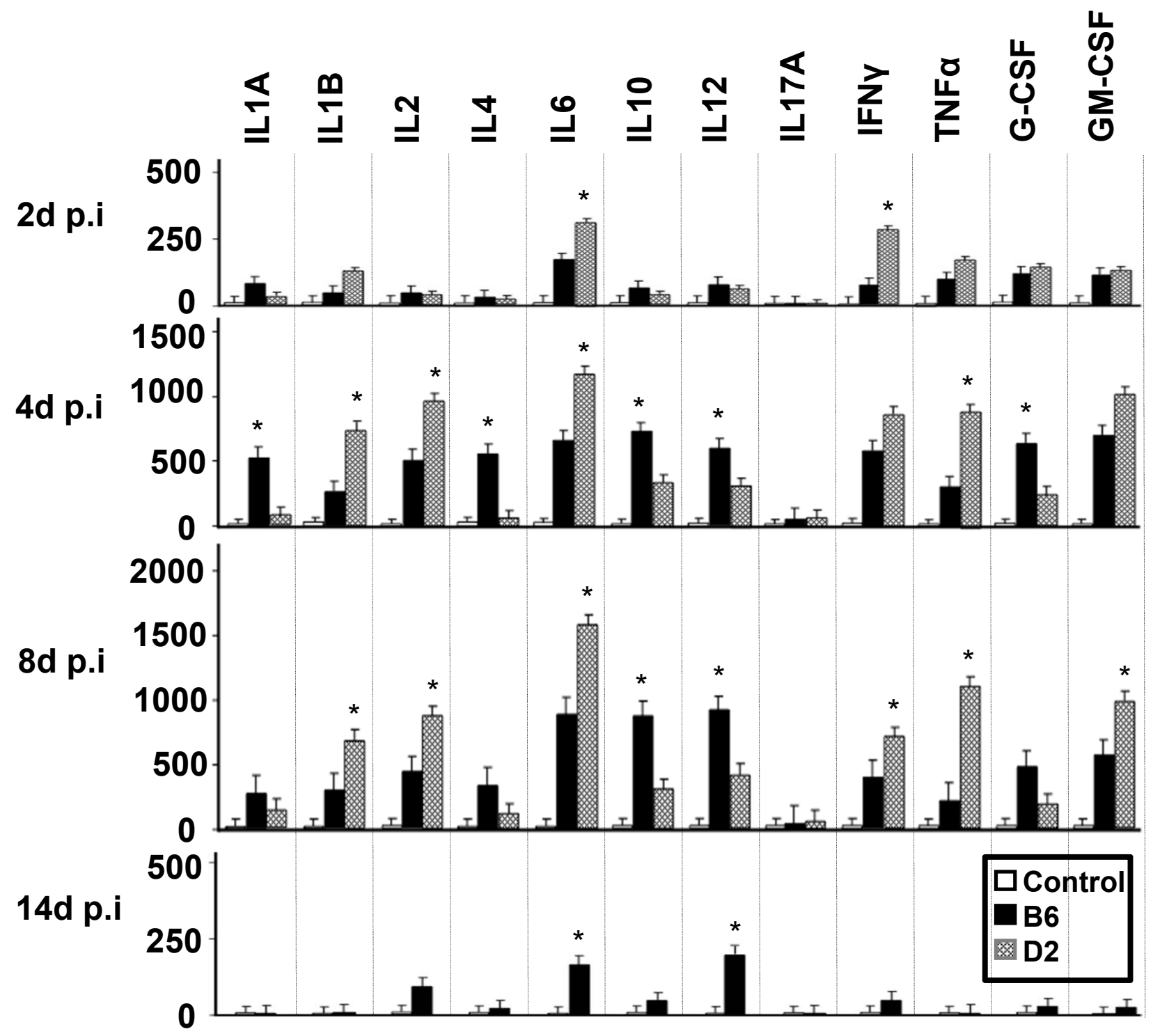

$\mathrm{pg} / \mathrm{ml}$ 
FIG 4

Simon AY et al

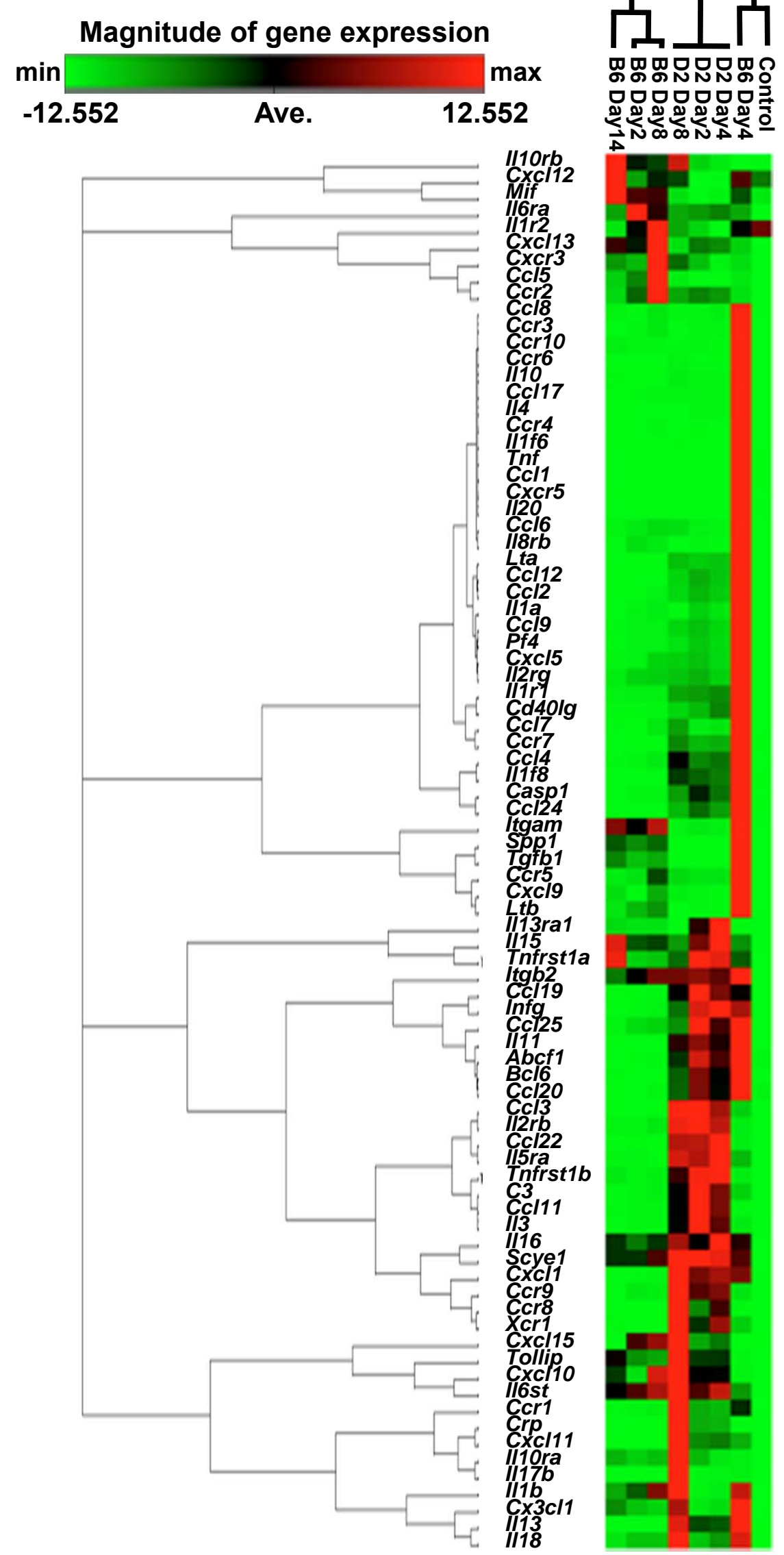


FIG 5

(A)

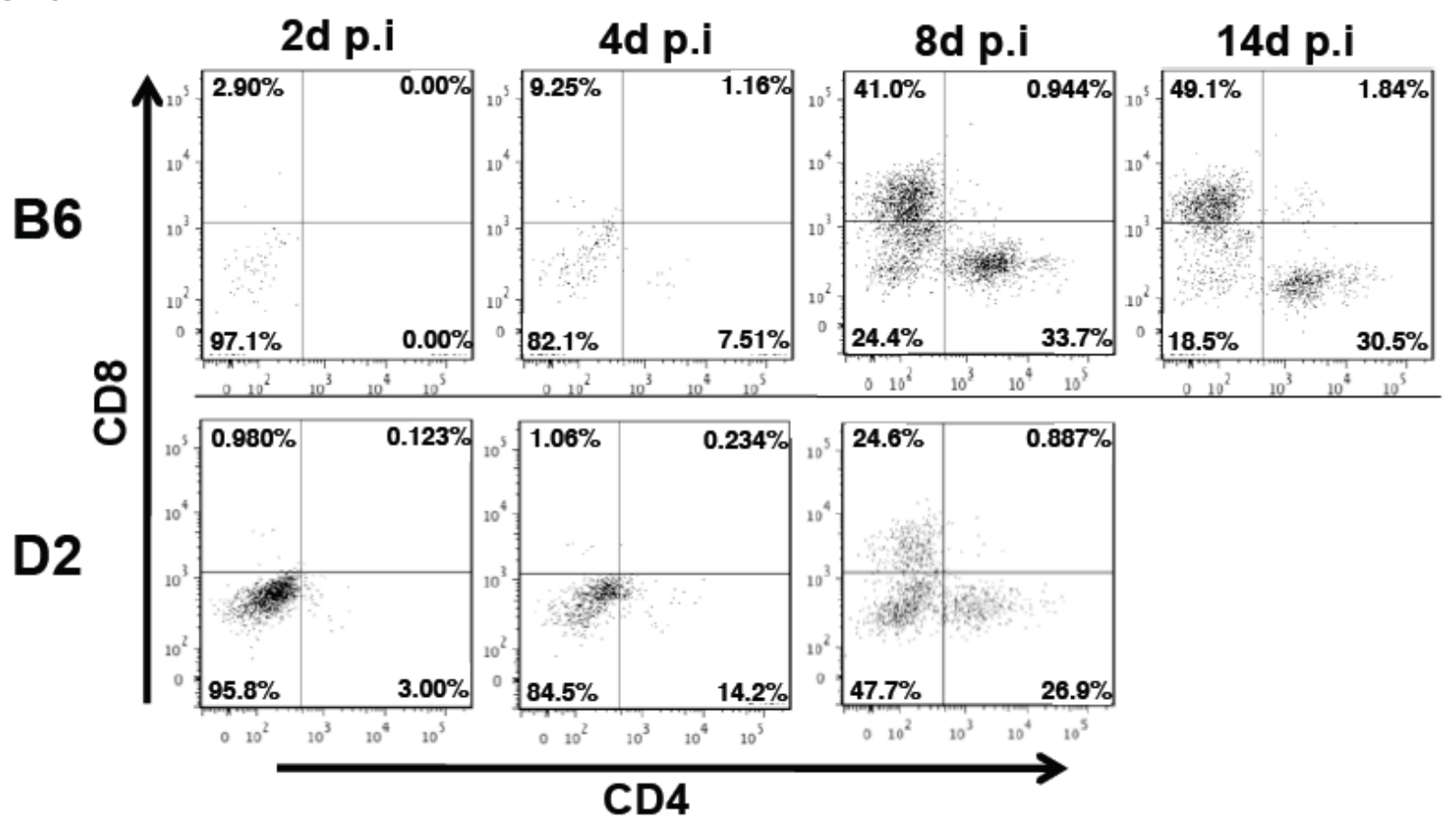

(B)

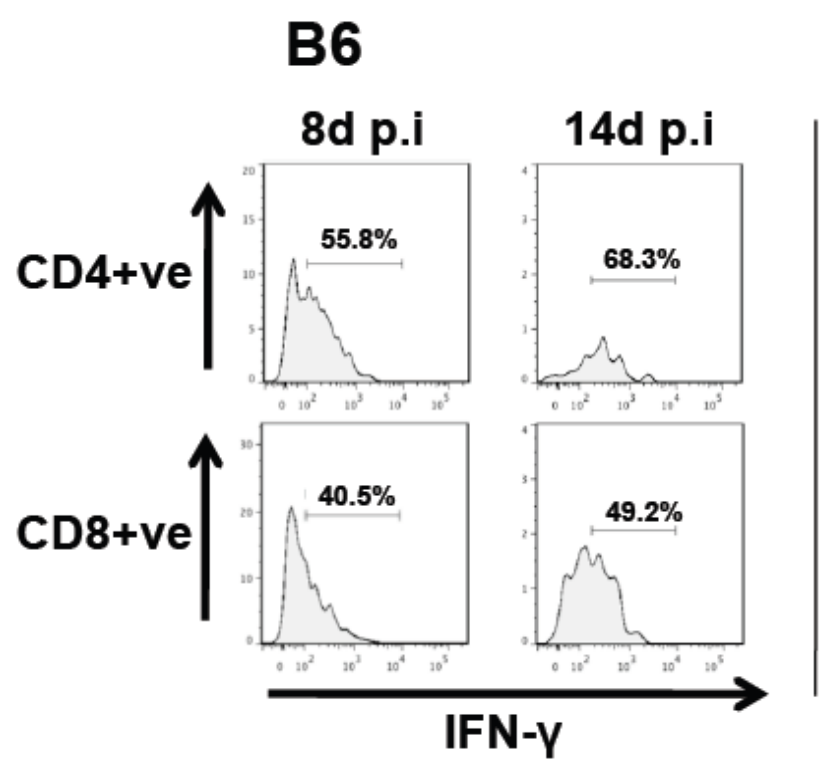

D2

(C)

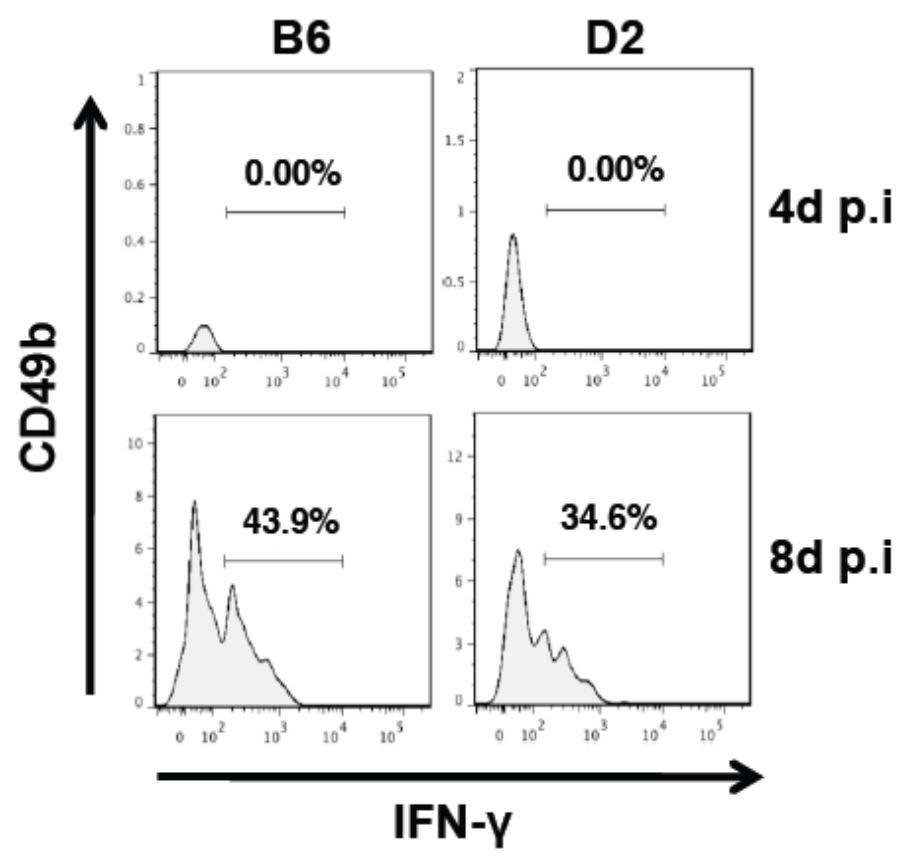


(D)

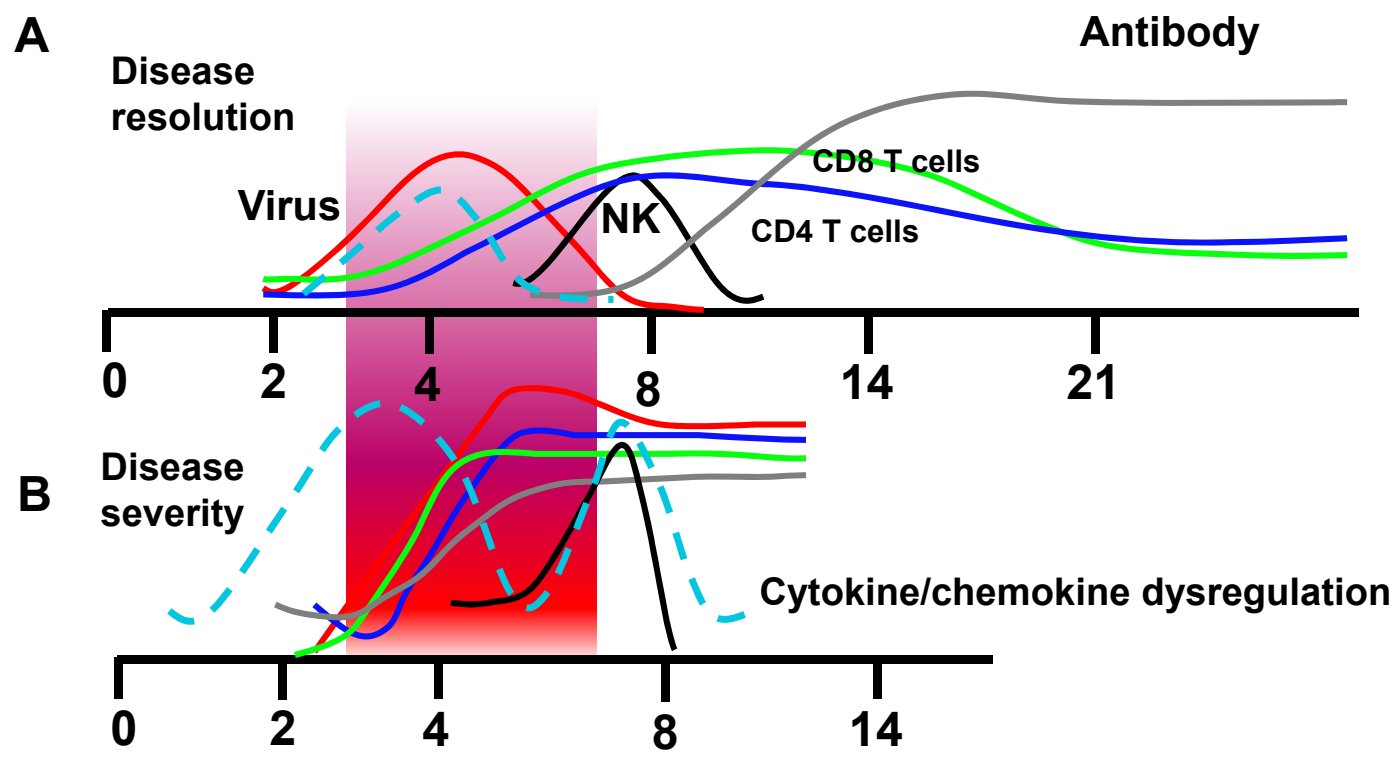




\begin{tabular}{|c|c|c|c|c|}
\hline $\begin{array}{l}\text { Accession No. } \\
\text { Chemokine gen }\end{array}$ & Gene Symbol & Gene Description & Up or Down & $P$-value \\
\hline NM_011329 & $\mathrm{Ccl1}$ & Chemokine (C-C motif) ligand 1 & 2.18 & 0.638 \\
\hline NM_011330 & Ccl11 & Chemokine (C-C motif) ligand 11 & 7.3 & $0.000^{\star}$ \\
\hline NM_011331 & Ccl12 & Chemokine (C-C motif) ligand 12 & 5.97 & 0.122 \\
\hline NM_011332 & Ccl17 & Chemokine (C-C motif) ligand 17 & 2.07 & 0.577 \\
\hline NM_011888 & Ccl19 & Chemokine (C-C motif) ligand 19 & 6.62 & $0.026^{*}$ \\
\hline NM_011333 & $\mathrm{Ccl} 2$ & Chemokine (C-C motif) ligand 2 & 4.02 & 0.186 \\
\hline NM_016960 & Ccl2O & Chemokine (C-C motif) ligand 20 & 6.62 & $0.052^{*}$ \\
\hline NM_009137 & Ccl22 & Chemokine (C-C motif) ligand 22 & 8.54 & $0.003^{\star}$ \\
\hline NM_019577 & Ccl24 & Chemokine (C-C motif) ligand 24 & 7.25 & 0.093 \\
\hline NM_009138 & Ccl25 & Chemokine (C-C motif) ligand 25 & 3.52 & 0.093 \\
\hline NM_011337 & $\mathrm{Ccl} 3$ & Chemokine (C-C motif) ligand 3 & 9.01 & $0.005^{\star}$ \\
\hline NM_013652 & Ccl4 & Chemokine (C-C motif) ligand 4 & 4.06 & 0.098 \\
\hline NM_013653 & Ccl5 & Chemokine (C-C motif) ligand 5 & -3.52 & $0.003^{\star}$ \\
\hline NM_013654 & Ccl7 & Chemokine (C-C motif) ligand 7 & 2.83 & 0.253 \\
\hline NM_011338 & Ccl9 & Chemokine (C-C motif) ligand 9 & 2.91 & $0.035^{\star}$ \\
\hline NM_008176 & Cxcl1 & Chemokine (C-X-C motif) ligand 1 & 6.45 & $0.038^{*}$ \\
\hline NM_021274 & Cxcl10 & Chemokine (C-X-C motif) ligand 10 & 3.12 & $0.027^{\star}$ \\
\hline NM_019494 & Cxc/11 & Chemokine (C-X-C motif) ligand 11 & 7.89 & 0.224 \\
\hline NM_011339 & Cxcl15 & Chemokine (C-X-C motif) ligand 15 & 6.58 & 0.29 \\
\hline NM_019932 & $\mathrm{Cxcl} 4$ & Chemokine (C-X-C motif) ligand 4 & 2.24 & 0.333 \\
\hline NM_009141 & Cxcl5 & Chemokine (C-X-C motif) ligand 5 & 2.09 & 0.089 \\
\hline \multicolumn{5}{|c|}{ Chemokine Receptors Genes } \\
\hline NM_009912 & Ccr1 & Chemokine (C-C motif) receptor 1 & 4.69 & 0.061 \\
\hline NM_009835 & Ccr6 & Chemokine (C-C motif) receptor 6 & 2.33 & 0.549 \\
\hline NM_007719 & Ccr7 & Chemokine (C-C motif) receptor 7 & 6.31 & 0.132 \\
\hline NM_007720 & Ccr8 & Chemokine (C-C motif) receptor 8 & 10.23 & $0.001^{\star}$ \\
\hline NM_009913 & Ccr9 & Chemokine (C-C motif) receptor 9 & 6.76 & $0.005^{\star}$ \\
\hline NM_011798 & Xcr1 & Chemokine (C motif) receptor 1 & 8.33 & $0.004^{*}$ \\
\hline \multicolumn{5}{|l|}{ Cytokine Genes } \\
\hline NM_008337 & Ifng & Interferon gamma & 6.59 & $0.050^{*}$ \\
\hline NM_008350 & $\| 111$ & Interleukin 11 & 4.26 & $0.050^{*}$ \\
\hline NM_008355 & $\| 13$ & Interleukin 13 & 8.89 & 0.077 \\
\hline NM_010551 & //16 & Interleukin 16 & 7.38 & $0.004^{*}$ \\
\hline NM_019508 & $/ 17 b$ & Interleukin $17 \mathrm{~b}$ & 2.58 & $0.050^{*}$ \\
\hline NM_008360 & //18 & Interleukin 18 & 2.23 & 0.19 \\
\hline NM_130058 & $1 / 1 f 8$ & Interleukin 1 family member 8 & 8.31 & 0.1 \\
\hline NM_010556 & II3 & Interleukin 3 & 2.83 & $0.003^{*}$ \\
\hline NM_010735 & Lta & Lymphotoxin A & 7.34 & 0.126 \\
\hline NM_007926 & Scye1 & Small inducible cytokine subfamilyE, member 1 & 2.58 & $0.005^{\star}$ \\
\hline NM_011616 & Cd4Olg & CD40 ligand & 3.83 & 0.151 \\
\hline NM_008401 & Itgam & Intergrin alpha $\mathrm{M}$ & -3.48 & $0.002^{*}$ \\
\hline NM_008518 & Ltb & Lymphotoxin B & -3.51 & $0.005^{\star}$ \\
\hline NM_009263 & Spp1 & Secreted phosphoprotein 1 & -7.06 & $0.000^{*}$ \\
\hline NM_011577 & Tgfb1 & Transforming growth factor, beta 1 & -5.78 & $0.003^{*}$ \\
\hline \multicolumn{5}{|c|}{ Cytokine Receptors Genes } \\
\hline NM_008348 & I/10ra & Interleukin 10 receptor, alpha & 2.26 & 0.079 \\
\hline NM_133990 & //13ra1 & Interleukin 13 receptor, alpha 1 & 2.58 & 0.33 \\
\hline NM_008362 & $\| 1 r 1$ & Interleukin 1 receptor, type 1 & 3.06 & 0.131 \\
\hline NM_008368 & II2rb & Interleukin 2 receptor, beta chain & 6.89 & $0.000^{*}$ \\
\hline NM_008370 & II5ra & Interleukin 5 receptor, alpha & 6.62 & $0.004^{*}$ \\
\hline NM_010560 & II6st & Interleukin 6 signal transducer & 2.87 & $0.005^{\star}$ \\
\hline NM_011609 & Tnfrsf1a & Tumor necrosis factor receptor subfamily, member 1a & 2.62 & $0.016^{*}$ \\
\hline NM_011610 & Tnfrsf1b & Tumor necrosis factor receptor subfamily, member $1 \mathrm{~b}$ & 6.15 & $0.000^{*}$ \\
\hline \multicolumn{5}{|c|}{ Other Genes Involved in inflammatory Response } \\
\hline NM_013854 & $A b c f 1$ & ATP-binding cassette, subfamily $\mathrm{F}$ member 1 & 5.23 & $0.053^{*}$ \\
\hline NM_009744 & $B c / 6$ & B-cell leukemia/lymphoma 6 & 6.28 & 0.06 \\
\hline NM_009778 & C3 & Complement component 3 & 6.18 & $0.004^{*}$ \\
\hline NM_009807 & Casp1 & Caspase 1 & 4.82 & 0.098 \\
\hline NM_007768 & Crp & C-reactive protein, pentraxin-related & 12.23 & $0.003^{*}$ \\
\hline NM_023764 & Tollip & Toll interacting protein & 3.23 & $0.034^{*}$ \\
\hline
\end{tabular}

